Article

\title{
Synthesis of the Novel Type of Bimodal Ceramic Nanowires from Polymer and Composite Fibrous Mats
}

\author{
Tomasz Tański * (10) and Wiktor Matysiak * \\ Institute of Engineering Materials and Biomaterials, Silesian University of Technology, Konarskiego 18a, \\ 44-100 Gliwice, Poland \\ * Correspondence: tomasz.tanski@polsl.pl (T.T.); wiktor.matysiak@polsl.pl (W.M.); \\ Tel.: +48-32-237-2509 (T.T.); +48-32-237-2603 (W.M.)
}

Received: 16 January 2018; Accepted: 15 March 2018; Published: 20 March 2018

\begin{abstract}
The purpose of this paper was to produce $\mathrm{SiO}_{2}$ and $\mathrm{TiO}_{2}$ nanowires via the electrospinning process from a polyvinylpyrrolidone (PVP)/Tetraethyl orthosilicate (TEOS)/Titanium (IV) butoxide (TNBT)/dimethylformamide (DMF) and ethanol (EtOH) solution. The as-obtained nanofibers were calcined at temperatures ranging from $400{ }^{\circ} \mathrm{C}$ to $600{ }^{\circ} \mathrm{C}$ in order to remove the organic phase. The one-dimensional ceramic nanostructures were studied using a scanning electron microscope (SEM) and a transmission electron microscope (TEM) to analyze the influence of the used temperature on the morphology and structures of the obtained ceramic nanomaterials. In order to examine the chemical structure of the nanowires, energy dispersive spectrometry (EDX) and Fourier-Transform Infrared spectroscopy (FTIR) were used. The optical property analysis was performed on the basis of UV-Vis spectra of absorbance as a function of the wavelength. Using the modified Swanepoel method, which the authors proposed and the recorded absorbance spectra allowed to determine the banded refractive index $n$, real $n^{\prime}$ and imaginary $k$ part of the refractive index as a function of the wavelength, complex dielectric permeability $\varepsilon$, and real and imaginary part $\varepsilon_{r}$ and $\varepsilon_{i}$ of the dielectric permeability as a function of the radiation energy of the produced ceramic nanowires.
\end{abstract}

Keywords: $\mathrm{SiO}_{2}$ nanowires; $\mathrm{TiO}_{2}$ nanowires; bimodal nanowires; electrospinning; Zol-gel method; optical properties

\section{Introduction}

Over the last fifteen years, one-dimensional structures of simple oxides particularly titanium oxide $\left(\mathrm{TiO}_{2}\right)$ [1-4] and silicon oxide $\left(\mathrm{SiO}_{2}\right)$ have been particularly popular in the field of both scientific research and expected wide application possibilities [5-8]. Unlike other zero-dimensional, two-dimensional, or three-dimensional nanostructures, nanowires have two limited quantum directions resulting from their nanometer diameter due to which electrons can easily move in a precisely defined direction, which is determined by the length of a single nanowire. This allows for the use of this structure in elements in which the main challenge is to conduct electricity excluding the tunneling transition. In addition, due to very high energy densities occurring in single-dimensional oxide nanomaterials resulting from the nanometric diameters of individual nanowires, these materials exhibit extremely different and better optical, magnetic, and electrical properties in abducting their counterparts in the micrometer scale [9]. To date, many techniques have been developed for producing nanowires and ceramic nanofibers. The most commonly used ones are physical vapor deposition (PVD), chemical vapor deposition (CVD), and thermal decomposition in which the growth of nanostructures is caused by vapor-liquid-solid (VLS) or solid-liquid-solid (SLS) mechanisms [10-15]. These methods allow to fully control the morphology of one-dimensional nanomaterials, but the production costs 
when using these methods are too high. This makes it unprofitable to use them to produce nanowires and oxide nanofibers on an industrial scale. The method of obtaining one-dimensional ceramic nanostructures based on the combination of sol-gel technology and spinning of the prepared sol in a strong electrostatic field is becoming more and more valued [16-23]. This process does not require complicated operations and expensive, technically advanced equipment. In addition, it is characterized by low production costs combined with the possibility of producing nanostructures on an industrial scale. In addition, by selecting the electrospinning process parameters such as the distance and voltage between the nozzle and collector as well as the spinning solution feed rate through the device pump, (see Figure 1) as well as the spinning solution parameters such as conductivity, viscosity, and precursor concentration and the conditions of the calcination process in the subsequent production stage of one-dimensional Ceramic nanostructures, it is possible to obtain nanowires and ceramic nanotubes characterized by a fully controlled and defined morphology. The ceramic nanostructures obtained in this way can be a more effective and more economical alternative to nanowires produced using conventional methods, which are increasingly used to build a new generation of photovoltaic cells, filters, or sensors.

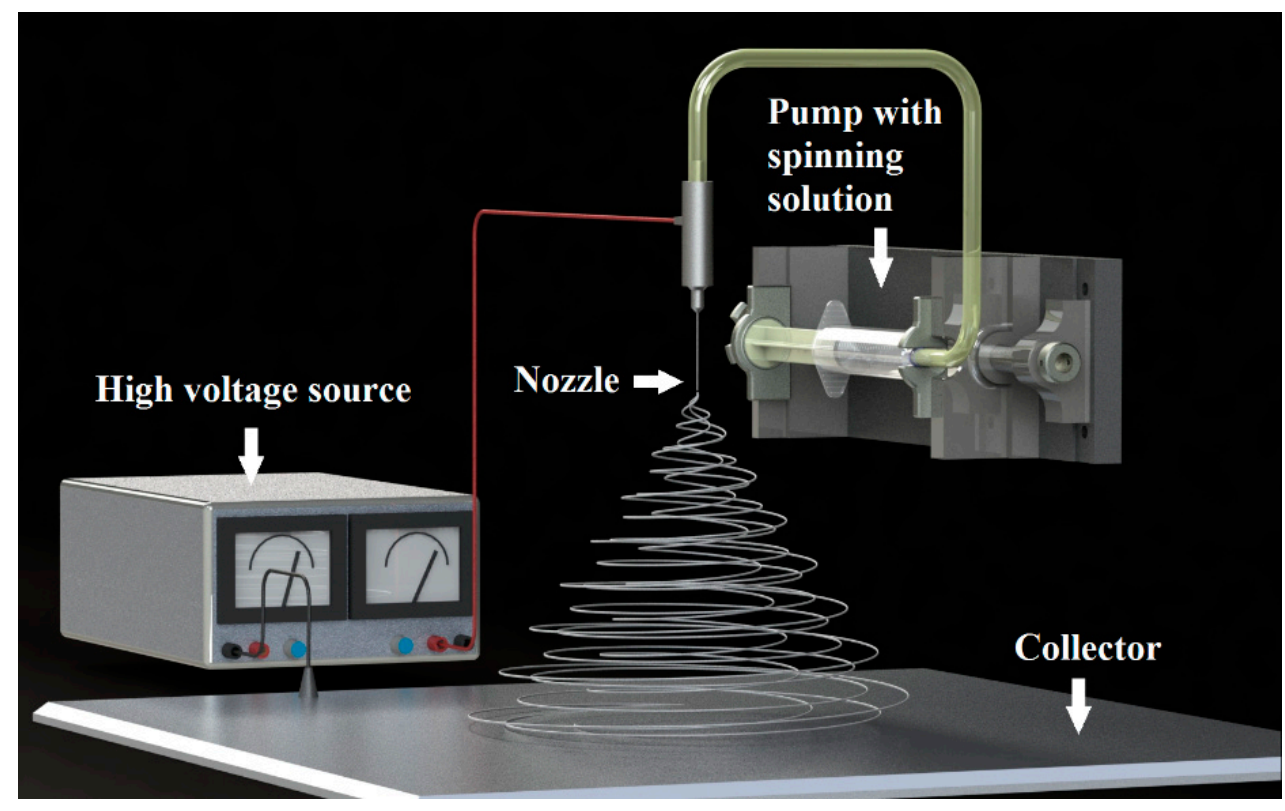

Figure 1. The scheme of the preparation of one-dimensional nanostructures by electrospinning.

So far, dye photovoltaic cells built on the basis of electrodes consisting of titanium dioxide nanostructures achieve the highest efficiency in converting solar energy into electricity-up to $11 \%$ on a laboratory scale. $\mathrm{TiO}_{2}$ is the ideal material for this type of application due to its physical properties such as the energy gap width of 3-3.4 eV, the refractive index at 2-2.5, the electric permittivity value of 8.5 , and the ability for the formation of crystalline structures such as rutile, anatase, and brookite [24]. One-dimensional nanostructures of titanium oxide have already found their application as materials for photo-electrochemical water splitting [25] and oxidation [26] as well as the base for composite materials used for environmental purification [27] and photo-electrochemical hydrogen generation [28]. In turn, as demonstrated by Nishikawa et al., at room temperature silicon oxide is characterized by six photoluminescent bands in the energy range from 1.9 to $4.3 \mathrm{eV}$ due to excitations induced by a $7.9 \mathrm{eV}$ excimer laser [29]. Radiation emitted through amorphous $\mathrm{SiO}_{2}$ nanowires corresponding to visible light with a blue and green color allows the use of this type of nanostructures as novel green-emitting phosphor [30] or materials for the construction of full-color display [31]. In addition, stable phase change materials made on the basis of one-dimensional $\mathrm{SiO}_{2}$ nanostructures obtained using the sol-gel method and electrospinning showed high efficiency of heat energy collection and 
storage [32]. Additionally, nanofibrous $\mathrm{SiO}_{2}$ mats as well as composite materials produced with their participation are successfully used to build innovative, flexible lithium-ion batteries [33] and water filters, which allows the adsorption of toxic cationic and anionic dyes. This is possible due to the high porosity and specific surface of the nano-structured silica [34].

The purpose of the presented work is to create modern ceramic nanostructures in the form of bimodal nanowires with titanium oxide and silicon oxide matrices containing nanoparticles of the same oxide as the matrix as well as to determine the impact of the applied nanoparticles and calcination temperatures on the morphology, structure, and optical properties of the obtained bimodal nanowires of $\mathrm{SiO}_{2} / \mathrm{SiO}_{2}$ and $\mathrm{TiO}_{2} / \mathrm{TiO}_{2}$.

\section{Materials and Methods}

\subsection{Materials}

To prepare spinning solutions and produce one-dimensional nanostructures, we used poly (vinylpyrrolidone) (PVP, 99\% pure, $\left.M_{\mathrm{W}}=1,300,000 \mathrm{~g} / \mathrm{mole}\right)$, ethanol (EtOH, 99.8\% purity), acetic acid (AcOH, 99.8\% purity), and titanium (IV) butoxide (TNBT, purity 98\%), tetraethoxysilane (TEOS, purity 99\%), and deionized water (H2OEthyl alcohol was supplied by Avantor Performance Materials Poland (Gliwice, Poland). Other reagents and polymers were purchased from Sigma-Aldrich (Poznan, Poland). In order to obtain bimodal $\mathrm{SiO}_{2} / \mathrm{SiO}_{2}$ nanostructures, $\mathrm{SiO}_{2}$ nanoparticles were additionally used at the stage of the spinning solution preparation while, in the case of the $\mathrm{TiO}_{2} / \mathrm{TiO}_{2}$ bimodal nanostructures, the nanofillers were $\mathrm{TiO}_{2}$ nanoparticles. The applied nanopowders were characterized by the author in the work [35].

\subsection{Methods}

In the first step of preparing the spinning solutions to obtain $\mathrm{SiO}_{2}$ nanowires and bimodal $\mathrm{SiO}_{2} / \mathrm{SiO}_{2}$ nanowires, two identical $10 \%(w / w)$ of polymer/ethanol mixtures were produced by adding $3.825 \mathrm{~g}$ of PVP to $50 \mathrm{~mL}$ of $\mathrm{EtOH}$, where, for one of the solutions, before adding the polymer to ethanol, a metered amount of $\mathrm{SiO}_{2}$ nanoparticles of $1.095 \mathrm{~g}$, which corresponds to $25 \%$ of the weight concentration of nanoparticles relative to the polymer mass, was added. This was followed by sonication for $1 \mathrm{~h}$ to break up the agglomerates of the applied nano powder. Two milliliters of $\mathrm{H}_{2} \mathrm{O}$ were added to the mixture and then everything was stirred in magnetic stirrers for $60 \mathrm{~min}$. In the next step, a mixture of $4 \mathrm{~mL}$ of TEOS with $4.66 \mathrm{~mL}$ of $\mathrm{AcOH}$ was added to each solution and it was further stirred for $24 \mathrm{~h}$. In the case of the preparation of spinning solutions to obtain $\mathrm{TiO}_{2}$ nanowires and bimodal $\mathrm{TiO}_{2} / \mathrm{TiO}_{2}$ nanowires, two equal $10 \%$ (by weight) polymer blends in ethanol were also prepared by adding $3.825 \mathrm{~g}$ of PVP to $50 \mathrm{~mL}$ of EtOH. In the case of one of the solutions, before adding the polymer to ethanol, a measured amount of $1.095 \mathrm{~g}$ of $\mathrm{TiO}_{2}$, which correspond to $25 \%$ of the weight concentration of nanoparticles relative to the weight of the polymer nanoparticles, was added and the whole was sonicated for $1 \mathrm{~h}$ to break up the agglomerates of the used reinforcing phase. The prepared mixtures were mixed in magnetic stirrers for $60 \mathrm{~min}$. In the next step, a mixture of $4 \mathrm{~mL}$ of TNBT with $4.66 \mathrm{~mL}$ of $\mathrm{AcOH}$ was added to each solution and further stirred for $24 \mathrm{~h}$.

Immediately after the mixing was completed, the solutions were placed in the device's pump and subjected to electrospinning. The nanofibers were obtained with the use of the FLOW-Nanotechnology Solutions Electrospinner 2.2.0-500 device (Yflow, Malaga, Spain) using the following process parameters: solution flow rate of $2.5 \mathrm{~mL} / \mathrm{h}$, potential difference between electrodes of $20 \mathrm{kV}$, and distance between electrodes of $17.5 \mathrm{~cm}$ for solutions containing $\mathrm{SiO}_{2}$ and $15 \mathrm{~cm}$ in the case of $\mathrm{TiO}_{2}$.

Immediately after production, the fibrous mats were allowed to dry at room temperature and then they were subjected to the calcination process in a HT-2100-G-Vac-Graphit-Special high-temperature vacuum furnace oven (Linn, Bad Frankenhausen, Germany) at temperatures of $400{ }^{\circ} \mathrm{C}, 500{ }^{\circ} \mathrm{C}$, and $600{ }^{\circ} \mathrm{C}$ in an air atmosphere for a time of $3 \mathrm{~h}$. In all cases, the heating speed was $10^{\circ} \mathrm{C} / \mathrm{min}$ and, after heating, the samples remained in the furnace until it cooled down. 
In order to analyze the morphology and structure of the produced one-dimensional ceramic nanostructures, a high-resolution transmission electron microscope TITAN 80-300 from FEI (Hillsboro, OR, USA) was used, which enabled imaging in transmission and scanning-transmission modes by using light and dark fields (BF, DF), HAADF detector, and filtration energy in particular with the use of analytical microscopy in nano areas in STEM mode.

In addition, single-dimensional ceramic nanostructures were quantitatively and qualitatively analyzed using Fourier-Transform Infrared spectroscopy (FTIR) (Nicolet ${ }^{\mathrm{TM}}$ iS ${ }^{\mathrm{TM}} 50$ FTIR Spectrometer, Thermo Fisher Scientific, Waltham, MA, USA) as well as X-ray EDX microanalysis (Trident XM4, EDAX, Weiterstadt, Germany) and surface topography imaging using a Zeiss Supra 35 scanning electron microscope (Zeiss, Oberkochen, Germany) with an X-ray Trident XM4 spectrometer provided by EDAX. Based on the taken SEM images, the diameters of one hundred randomly selected nanowires were measured using the Digital Micrograph program (2.32.888.0 version, GATAN, Pleasanton, CA, USA). Then their average value and chemical composition were determined based on EDX spectra.

To test the optical properties of $\mathrm{TiO}_{2}$ and $\mathrm{SiO}_{2}$ nanowires as well as bimodal $\mathrm{TiO}_{2} / \mathrm{TiO}_{2}$ and $\mathrm{SiO}_{2} / \mathrm{SiO}_{2}$ nanowires, they were applied to silicon substrates and then they were subjected to UV-Vis spectroscopic analysis. Measurements of the absorbance of the obtained materials as a function of the length of electromagnetic radiation incident on the sample were carried out using a Thermo-Scientific UV/VIS Evolution 220 spectrophotometer (Thermo Fisher Scientific, Waltham, MA, USA). Then, based on absorption spectra, the values of the band gap width, complex refractive index $n^{\prime}$, refractive index $n$ as a function of the wavelength, extinction coefficient $k$ as a function of the wavelength, complex electrical constant, and real and imaginary part of the etheric constant $\varepsilon_{r}$ and $\varepsilon_{i}$ as a function of the wavelength were all calculated.

\subsection{Theory}

Electromagnetic radiation falling on any material medium can penetrate, reflect, or be absorbed by it when the energy carried by given radiation quanta is equal to the energy difference between the energy states of the atoms of the studied medium. The degree of the reflection of electromagnetic radiation from a sample is determined by the so-called reflectance, which is defined as the ratio of the reflected beam power and the beam of the material falling on a given medium. Transmittance, on the other hand, is defined as the ratio of the beam power after passing through a given center to the power of the beam falling on it. Starting from the Lambert-Beer law and the relationship between absorbance $(A)$ and transmittance $(T)$, one obtains Equation (1).

$$
A=\log \frac{I_{0}}{I}=-\log (T)
$$

Using the recorded absorbance spectra as a function of length and the above equation, it is possible to determine transmittance as a function of the wavelength, which is observed in Equation (2).

$$
T(\lambda)=10^{-A(\lambda)}
$$

Based on the above dependence and equality:

$$
\left\{h v\left[\ln \left(\frac{1}{T(\lambda)}\right)\right]\right\}^{2}=[\alpha(\lambda) h \nu]^{2}
$$

where $h$ is the Planck constant and $v$ is the frequency of incident radiation per sample. Using Equation (3), we define Equation (4) and the relationship between the absorption coefficient and the extinction coefficient.

$$
\alpha(\lambda)=\ln \left(\frac{1}{T(\lambda)}\right)
$$


Equation (5) is calculated by using Equation (4) and the relationship between the absorption coefficient and the extinction coefficient.

$$
\alpha(\lambda)=\frac{4 \pi k(\lambda)}{\lambda}
$$

An expression is obtained for the extinction coefficient as a function of the wavelength.

$$
k(\lambda)=\frac{1}{4 \pi} \lambda \ln \frac{1}{T(\lambda)}
$$

By plotting the determined dependence of transmittance (2) as a function of the wavelength of radiation incident on the sample, it can be seen that the spectrum is characterized by interference occurring at higher transmittance values (see Figure 2). The location of emerging interference maxima and minima of the $T(\lambda)$ function is related to the actual part of the complex refractive index.

$$
n^{\prime}=n+i k
$$

where $n$-the real part of the refractive index; $i$ and $k$-is the extinction coefficient.

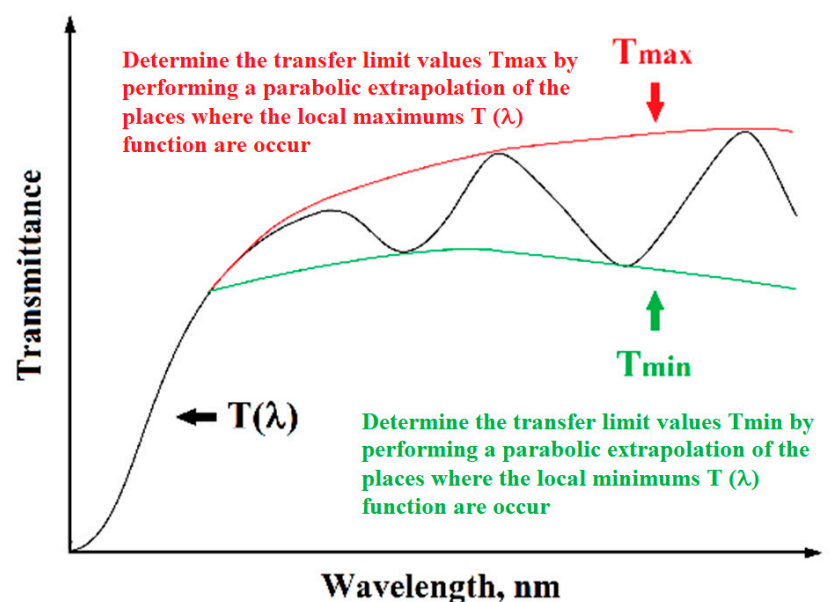

Figure 2. Schematic spectrum of transmittance as a function of the wavelength of a thin layer on a transparent substrate with visible local interference maxima and minima.

Using the R. Swanepoel method [36], which is limited to application only for thin layers deposited on a transparent substrate whose thickness is much greater than the thickness of the layer being tested, this condition is met for samples examined by the authors of this monograph. Based on the determined spectrum $T(\lambda)$, the next step is to determine the transfer limit values $T_{\max }$ and $T_{\min }$ by performing a parabolic extrapolation of the places where the maximum and minimum queues occur (see Figure 2). After determining the limit values $T_{\max }$ and $T_{\min }$ using the dependence, Equation (8) is calculated below.

$$
n^{\prime}=\left\{2 n_{p} \frac{T_{\max }-T_{\min }}{T_{\max } T_{\min }}+\frac{n_{p}^{2}+1}{2}+\left[\left(2 n_{p} \frac{T_{\max }-T_{\min }}{T_{\max } T_{\min }}+\frac{n_{p}^{2}+1}{2}\right)^{2}-n_{p}^{2}\right]^{\frac{1}{2}}\right\}^{\frac{1}{2}}
$$

where $n_{p}$-is the refractive index of the substrate used, which includes the determined complex refractive index of the studied one-dimensional oxide nanostructures.

In addition, based on the dependencies:

$$
n^{\prime}=\varepsilon^{\frac{1}{2}}
$$


A complex dielectric permittivity coefficient can be determined, which takes the form of Equation (10).

$$
\varepsilon \prime=2 n_{p} \frac{T_{\max }-T_{\min }}{T_{\max } T_{\min }}+\frac{n_{p}^{2}+1}{2}+\left[\left(2 n_{p} \frac{T_{\max }-T_{\min }}{T_{\max } T_{\min }}+\frac{n_{p}^{2}+1}{2}\right)^{2}-n_{p}^{2}\right]^{\frac{1}{2}}
$$

Based on the derived dependence of the extinction coefficient as a function of the wavelength of electromagnetic radiation incident on the sample $k(\lambda)$ and the determined reflection spectrum $R(\lambda)$, Equation (11) is determined.

$$
A(\lambda)+T(\lambda)+R(\lambda)=1
$$

The real part of the refractive index of the tested one-dimensional materials can be determined. The real part of the refractive index takes the form of Equation (12).

$$
n(\lambda)=\left\{\frac{4 R(\lambda)}{[R(\lambda)-1]^{2}}-\left[\frac{1}{4 \pi} \lambda \ln \frac{1}{T(\lambda)}\right]^{2}\right\}^{\frac{1}{2}}-\frac{R(\lambda)+1}{R(\lambda)-1}
$$

Using the relationship between the real $n(\lambda)$ and the imaginary $k(\lambda)$ part of the refractive index and complex dielectric permeability $\varepsilon_{r}(\lambda), \varepsilon_{i}(\lambda)$ has the form below.

$$
\begin{gathered}
\varepsilon_{r}(\lambda)=n(\lambda)^{2}-k(\lambda)^{2} \\
\varepsilon_{i}(\lambda)=2 n(\lambda) k(\lambda)
\end{gathered}
$$

The following equations describing the dependence between real $\varepsilon_{r}(\lambda)$ and imaginary $\varepsilon_{i}(\lambda)$ part of complex dielectric permittivity were obtained below.

$$
\begin{gathered}
\varepsilon_{r}(\lambda)=\left\{\left\{\frac{4 R(\lambda)}{[R(\lambda)-1]^{2}}-\left[\frac{1}{4 \pi} \lambda \ln \frac{1}{T(\lambda)}\right]^{2}\right\}^{\frac{1}{2}}-\frac{R(\lambda)+1}{R(\lambda)-1}\right\}^{2}-\left[\frac{1}{4 \pi} \lambda \ln \frac{1}{T(\lambda)}\right]^{2} \\
\varepsilon_{i}(\lambda)=2\left\{\left\{\frac{4 R(\lambda)}{[R(\lambda)-1]^{2}}-\left[\frac{1}{4 \pi} \lambda \ln \frac{1}{T(\lambda)}\right]^{2}\right\}^{\frac{1}{2}}-\frac{R(\lambda)+1}{R(\lambda)-1}\right\}\left[\frac{1}{4 \pi} \lambda \ln \frac{1}{T(\lambda)}\right]
\end{gathered}
$$

Based on the dependence of the absorption coefficient of the tested material as a function of the energy of incident radiation on its surface, which has the form below [37-39].

$$
\alpha h v=A\left(h v-E_{g}\right)^{\rho}
$$

where, $h$-the Planck constant, is the frequency of electromagnetic radiation, $E_{g}$-is the width of the energy gap of the tested material, $A$-it is a constant dependent on the probability of electron transitions, the values of the energy gap width of the produced one-dimensional oxide nanomaterials can be determined. In the case of coefficient $\rho$, various values, such as $1 / 2$ and $3 / 2$, are given for the available and the inaccessible direct inter-band transitions, and 2 and 3 for the successive and the forbidden intermediate transitions. However, the best results were achieved using an exponent equal to $\frac{1}{2}$ and such was assumed in this work. To determine the band width of the produced one-dimensional ceramic nanowires, the absorbance spectra obtained by means of the UV-Vis spectroscope were used as a function of the wavelength of incident per sample. In order to eliminate the influence of the substrate on which the layers of the produced nanowires were located, the absorption spectrum was measured for the substrate itself and, according to the law of absorption additivity, they were subtracted from the spectrum obtained for the layer of nanowires deposited on the substrate. For the spectra obtained in this way, using Equation (2), the spectra of the dependence of transmittance as a function of the 
wavelength were determined for all generated nanomaterials. After transformation, Equation (17) takes the following form.

$$
\left[h v \ln \left(\frac{1}{10^{-A B S}}\right)\right]^{2}=\mathrm{B}\left(h v-E_{g}\right)
$$

where $B$ is a constant dependent on the probability of electron transitions divided by the thickness of the examined layer. Then, dependencies $\left[h v \ln \left(\frac{1}{10^{-A B S}}\right)\right]^{2}$ were plotted in the energy function of radiation quanta for all generated nanomaterials and linear functions were adjusted to straight sections of graphs with the largest directional coefficients of a straight line. Zero sites were determined by calculating the absolute value of the ratio of free expressions to the directional coefficients of matched lines $(|\mathrm{b} / \mathrm{a}|)$ and corresponded to the width of energy gaps in the studied ceramic nanowires.

\section{Results and Discussion}

\subsection{TEM Analysis}

The analysis of the produced one-dimensional nanostructures, which was conducted using a high-resolution transmission electron microscope, has unambiguously confirmed that the use of a combination of the sol-gel method and electrospinning from solutions of $\mathrm{PVP} / \mathrm{TEOS} / \mathrm{EtOH} / \mathrm{AcOH}, \mathrm{PVP} / \mathrm{TEOS} / \mathrm{EtOH} / \mathrm{AcOH} / \mathrm{SiO}_{2} \mathrm{NPs}$, and PVP/TNBT/EtOH/AcOH, $\mathrm{PVP} / \mathrm{TNBT} / \mathrm{EtOH} / \mathrm{AcOH} / \mathrm{TiO}_{2} \mathrm{NPs}$ makes it possible to produce appropriately amorphous silicon oxide and titanium oxide nanowires as well as hybrid $\mathrm{SiO}_{2} / \mathrm{SiO}_{2} \mathrm{NPs}$ and $\mathrm{TiO}_{2} / \mathrm{TiO}_{2} \mathrm{NPs}$ nanowires. The use of three different calcination temperatures, specifically $400{ }^{\circ} \mathrm{C}, 500^{\circ} \mathrm{C}$, and $600{ }^{\circ} \mathrm{C}$, degraded the organic parts of hybrid fibrous mats, which were subjected to the electrospinning process. This contributed to the acquisition of amorphous nanowires of $\mathrm{SiO}_{2}$ and $\mathrm{TiO}_{2}$ regardless of the temperature applied (see Figures 3 and 4).

The diffractive spectrum of electrons in the form of diffractive reflexions shaped like fuzzy orbs was obtained for silicon oxide nanowires and produced as a result of calcination of PVP/TEOS nanofibers at a temperature of $600{ }^{\circ} \mathrm{C}$ as well as composite PVP/TEOS nanofibers that contained nanoparticles of silicon oxide, which is evidence of their amorphous structure (see Figure $3 c, f)$. The obtained $\mathrm{SiO}_{2}$ materials can be considered as amorphous nanowires with a diameter of approximately $100 \mathrm{~nm}$ and a length of no more than $1 \mu \mathrm{m}$. The analysis of the morphology of the studied hybrid ceramic $\mathrm{SiO}_{2} / \mathrm{SiO}_{2} \mathrm{NPs}$ nanostructures, which was conducted on the basis of the registered TEM images, showed an even dispersion of the applied reinforcing phase in the entire volume of single silica nanowires (see Figure 3d,e).

The analysis of the structure and morphology of a single $\mathrm{TiO}_{2}$ nanostructure, which is visible in Figure $4 a, b$, unambiguously shows that the obtained structure can be defined as a one-dimensional structure in the form of a nanowire with a diameter of $500 \mathrm{~nm}$ and a length of approximately $3 \mu \mathrm{m}$. Moreover, the ratio of the diameter to the length of the obtained one-dimensional structure of $\mathrm{TiO}_{2}$ allows the classification of the produced nanomaterial as a nanowire. The diffractive spectrum of electrons was obtained for a single $\mathrm{TiO}_{2}$ nanowire in the form of diffractive reflexions shaped like fuzzy orbs and created as a result of the dispersion of the electron beam. This is evidence of their amorphous structure (see Figure 4c). The addition of titanium oxide nanoparticles to the spinning solution of $\mathrm{PVP} / \mathrm{TNBT} / \mathrm{EtOH} / \mathrm{AcOH}$ allowed to obtain composite $\mathrm{PVP} / \mathrm{TEOS} / \mathrm{TiO}_{2} \mathrm{NPs}$ nanowires, which allowed us to obtain bimodal ceramic $\mathrm{TiO} / \mathrm{TiO}_{2} \mathrm{NPs}$ nanowires as a result of the conducted calcination process (see Figure $4 \mathrm{~d}, \mathrm{e}$ ). The analysis of the structure and morphology of the produced titanium oxide nanowires reinforced with $\mathrm{TiO}_{2}$ nanoparticles showed an even dispersion of the reinforcing phase in the entire volume of single bimodal, semi-conductive nanostructures (see Figure 3). The electronogram obtained for the bimodal $\mathrm{TiO}_{2}$ nanowires shows a collection of diffraction images from the amorphous matrix of titanium oxide as well as diffractive reflexions from plains with the following Miller's indexes: (125), (121), (220), (020) and (011), corresponding to the structure of nanocrystalline anatase, which was displayed by the used titanium oxide nanoparticles and played the role of the reinforcing phase. 

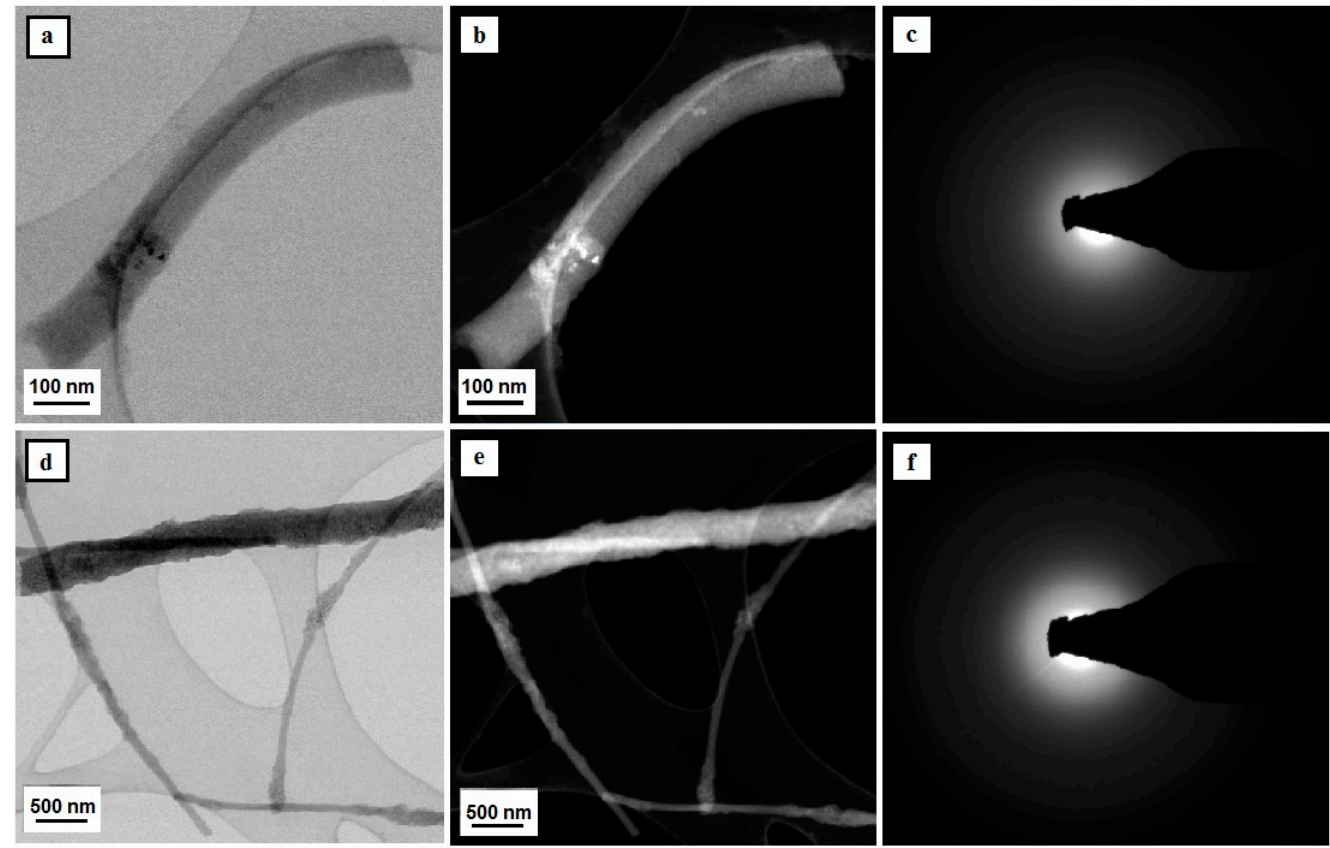

Figure 3. TEM images of the tested nanostructures $-\mathrm{SiO}_{2}$ nanowires comprising a matrix for $\mathrm{SiO}_{2} / \mathrm{SiO}_{2}$ NPs bimodal nanowires $(\mathbf{a}, \mathbf{b}, \mathbf{d}, \mathbf{e})$ along with diffraction images obtained with the use of analytical microscopy in nano areas in STEM mode and solved electronograms for nanoparticles and nanowires of silicon oxide $(\mathbf{c}, \mathbf{f})$.
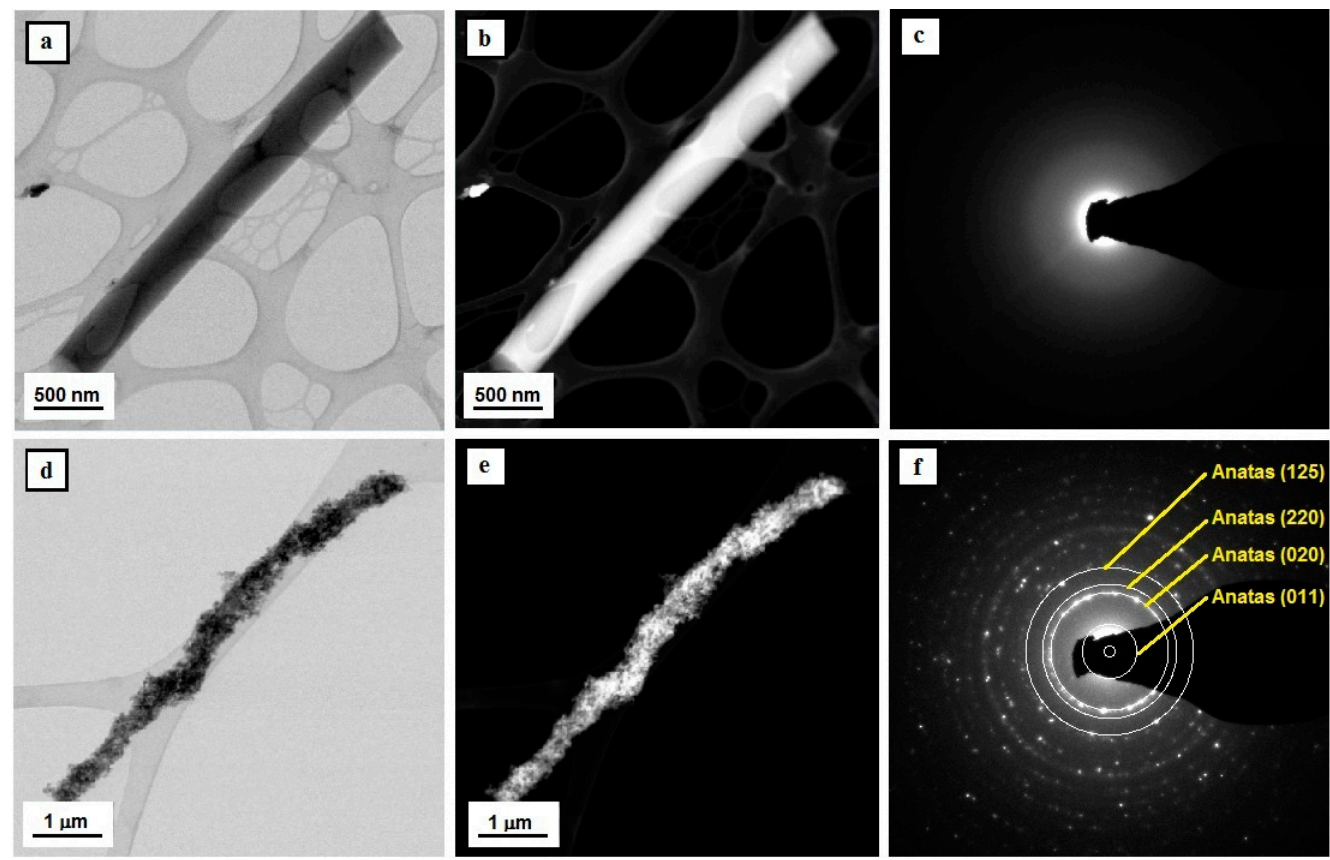

Figure 4. TEM images of the tested nanostructures- $\mathrm{TiO}_{2}$ nanowires comprising a matrix for $\mathrm{TiO}_{2} / \mathrm{TiO}_{2}$ NPs bimodal nanowires $(\mathbf{a}, \mathbf{b}, \mathbf{d}, \mathbf{e})$ along with diffraction images obtained with the use of analytical microscopy in nano areas in STEM mode and solved electronograms for nanoparticles and nanowires of titanium oxide $(\mathbf{c}, \mathbf{f})$. 


\subsection{FTIR Analysis}

The absorbance spectra in the function of the wavenumber in the range of 2000 to $400 \mathrm{~cm}^{-1} \mathrm{graphs}$ were plotted for the all groups of the obtained ceramic and bimodal one-dimensional nanostructures with some characteristic peaks for individual vibration molecules or functional groups (see Figure 5). FTIR examination of pure one-dimensional silica structures reveals two bond types occurring in the chemical structure of $\mathrm{SiO}_{2}$ nanowires including $\mathrm{Si}-\mathrm{O}-\mathrm{Si}$ and $\mathrm{Si}-\mathrm{O}$, which correspond to the following values of the wavenumber: $451,802,964$, and $1072 \mathrm{~cm}^{-1}$, respectively. This coincides with the results obtained in the works $[40,41]$. In addition, the peaks obtained in the FTIR spectrum, which were obtained for bimodal $\mathrm{SiO}_{2} / \mathrm{SiO}_{2}$ nanowires, correspond to the bonds present in the chemical structure of the reinforcing phase. $451 \mathrm{~cm}^{-1}$ corresponds to the rocking vibration type of Si-O while the peaks registered for frequencies of 802,964 , and $1076 \mathrm{~cm}^{-1}$ correspond to the stretching bond type of Si-O-Si [42] (Figure 5a,b). Moreover, Si-O-Si bonds are responsible for making $\mathrm{SiO}_{2}$ molecules. In the case of titanium oxide nanowires, the FTIR spectra show the Ti-O-Ti bond type, which corresponds to the wavenumber value of $440 \mathrm{~cm}^{-1}$. In addition, in the range of the wavenumber with a value of about $1600 \mathrm{~cm}^{-1}, \mathrm{OH}$ groups were observed, which correspond with the spectra obtained in the work [43] (see Figure 5c).
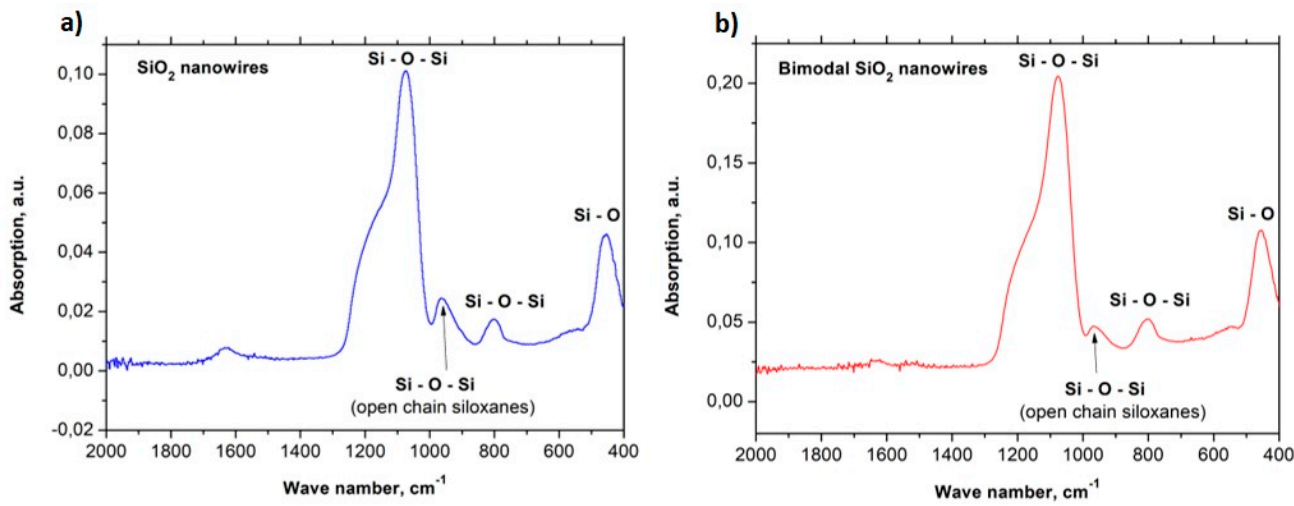

c)
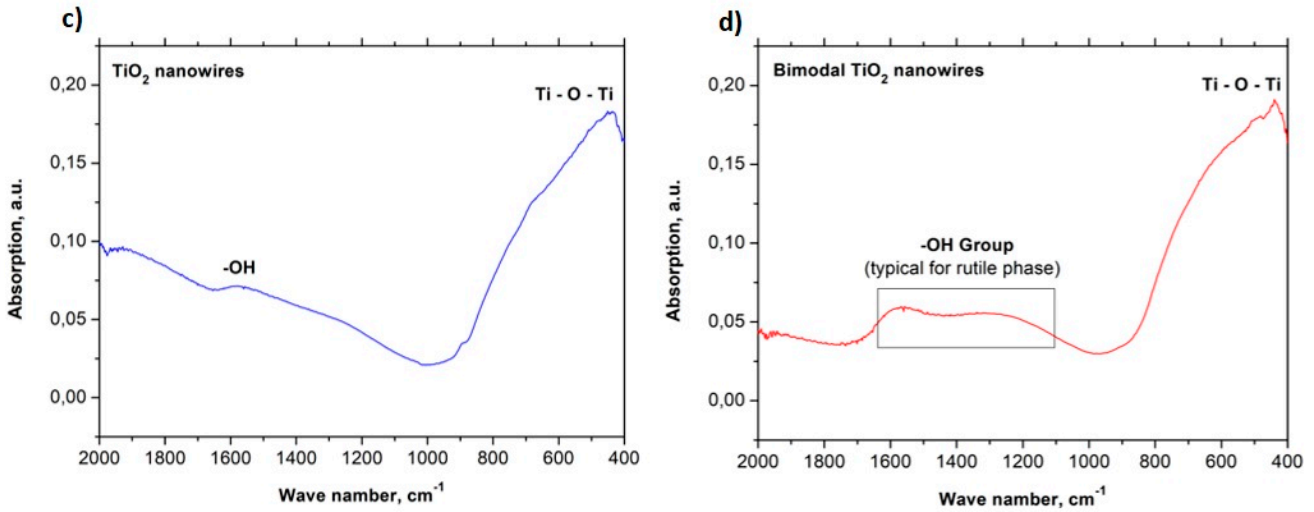

Figure 5. FTIR spectra for: (a) $\mathrm{SiO}_{2}$ nanowires, (b) bimodal $\mathrm{SiO}_{2}$ nanowires, (c) $\mathrm{TiO}_{2}$ nanowires, (d) bimodal $\mathrm{TiO}_{2}$ nanowires.

For bimodal $\mathrm{TiO}_{2}$ nanowires, absorption peaks were also observed, which correspond to Ti-O-Ti bonds as well as a significant extension of the spectrum indicative of $\mathrm{OH}$ groups (see Figure $5 \mathrm{~d}$ ). This phenomenon most likely results from the presence of evenly dispersed $\mathrm{TiO}_{2}$ nanoparticles in the amorphous matrix of titanium oxide nanowires. The increase of radiation absorption resulting from the presence of oxide particles can be explained by the increase of the specific surface area of the obtained nanostructures in comparison to $\mathrm{TiO}_{2}$ nanowires that do not contain nanoparticles inside of them or on their surface [42] as well as the crystal structure of rutile of the particles used [35]. The wide range of absorption, which corresponds to $\mathrm{OH}$ groups, is characteristic for $\mathrm{TiO}_{2}$ in the rutile phase 
and results from the bending vibration of chemically adsorbed water $[43,44]$. The results obtained for the FTIR analysis of the produced ceramic nanowires confirm the research results obtained with the use of a high-resolution transmission electron microscope, which proved the existence of $\mathrm{crystal}^{\mathrm{TiO}} 2$ nanoparticles in the amorphous matrix of titanium oxide nanowires.

\subsection{SEM Analysis}

In order to analyze the morphology and structure of the produced hybrid and composite nanofibers as well as the obtained oxide nanowires, imaging of the topography of the tested materials was carried out using a scanning electron microscope. Analysis of the morphology and structure of PVP/TEOS hybrid nanofibers obtained from a PVP/TEOS/EtoH/AcOH solution with 10\% share of polymer by weight showed that the obtained fibers constituting the starting material to produce silicon oxide nanowires were free of structural defects and had constant values of diameters along all their length (see Figure 5a).

A hundred-fold measurement of the diameters of the obtained PVP hybrid nanofibers containing TEOS precursor particles showed that the measured values ranged from $60 \mathrm{~nm}$ to $830 \mathrm{~nm}$ with the most frequent diameters ranging from $400 \mathrm{~nm}$ to $500 \mathrm{~nm}$, which accounted for $27 \%$ of all measured diameters. In addition, for this sample, the average diameter value was $371 \mathrm{~nm}$ (Figure 6a, histogram).

The next stage of the research consisted in calcination at three different temperatures of the obtained PVP/TEOS hybrid fibrous mats for three hours. This led to clean and defect-free structural nanowires of silicon oxide. This was confirmed by the analysis of the EDS spectra obtained for these materials (Figure $6 \mathrm{~b}-\mathrm{d}$-EDS spectra). Regardless of the temperature used during the calcination process, the obtained one-dimensional $\mathrm{SiO}_{2}$ nanostructures were characterized by a lack of structural defects and a hundred-fold diameter measurement of the obtained nanowires showed that the measured diameters were in close ranges of the nanoscale. The hybrid calcinations, by successively applying temperatures of $500{ }^{\circ} \mathrm{C}$ and $600{ }^{\circ} \mathrm{C}$, were allowed to produce $\mathrm{SiO}_{2}$ nanowires with diameters from $80 \mathrm{~nm}$ to $750 \mathrm{~nm}$ and from $80 \mathrm{~nm}$ to $830 \mathrm{~nm}$ (Figure $6 \mathrm{~b}-\mathrm{d}$-histograms). The temperature of polymer matrix degradation was increased in the calcined nanofibers where the average diameter value decreased and was $328 \mathrm{~nm}, 304 \mathrm{~nm}$, and $296 \mathrm{~nm}$, respectively. This fact indicates the possibility of controlling the morphology of the produced nanowires by changing the calcination temperature and obtaining amorphous $\mathrm{SiO}_{2}$ nanostructures in each case (Figure 5d-TEM images and diffraction spectrum). The addition of up to 10\% PVP/TEOS/EtoH/AcOH spinning solution of $\mathrm{SiO}_{2}$ nanoparticles resulted in an increase in the diameters of the obtained $\mathrm{PVP} / \mathrm{TEOS} / \mathrm{SiO} 2$ hybrid composite nanofibers by about $20 \mathrm{~nm}$ compared to fibers containing no silica nano powder as well as the formation of structural defects in the beads concentrating the agglomerates used as the nano filler (Figure 7a-picture SEM and histogram). Subjecting the obtained composite mat to a calcination process, at each temperature, allowed us to obtain bimodal $\mathrm{SiO}_{2}$ nanowires containing $\mathrm{SiO}_{2}$ nanoparticles within their volume and on their surface (Figure $7 \mathrm{~b}-\mathrm{d}$ and EDS spectra). In the case of bimodal silicon oxide nanowires, in contrast to the pure $\mathrm{SiO}_{2}$ nanostructures obtained from the PVP/TEOS solution, the temperature increase used during the calcination process led the range of recorded diameters of the tested one-dimensional nanostructures to decrease. However, after calcination at $400{ }^{\circ} \mathrm{C}$, the measured diameters of $\mathrm{SiO}_{2}$ did not exceed $900 \mathrm{~nm}$.

The application of subsequent temperatures allowed us to obtain nanowires with diameters not exceeding $800 \mathrm{~nm}\left(500^{\circ} \mathrm{C}\right)$ and $550 \mathrm{~nm}\left(600^{\circ} \mathrm{C}\right)$ (Figure $7 \mathrm{~b}-\mathrm{d}$-histograms). This fact indicates the possibility of controlling the morphology of the produced nanowires by changing the calcination temperature and obtaining amorphous $\mathrm{SiO}_{2}$ nanostructures in each case (Figure 6d-TEM images and diffraction spectrum) and adding the same phase of the nano powder to the spinning solution.

The analysis of the morphology and structure of the hybrid nanofibers of PVP/TNBT precursor molecules, which were obtained from PVP/TNBT/EtoH/AcOH solution with 10\% polymer concentration (by weight) and showed that these fibers have defects in the form of the so-called 
beads that were probably formed by the hydrolysis and condensation of the precursor particles already at the stage of the spinning solution (see Figure 8a).
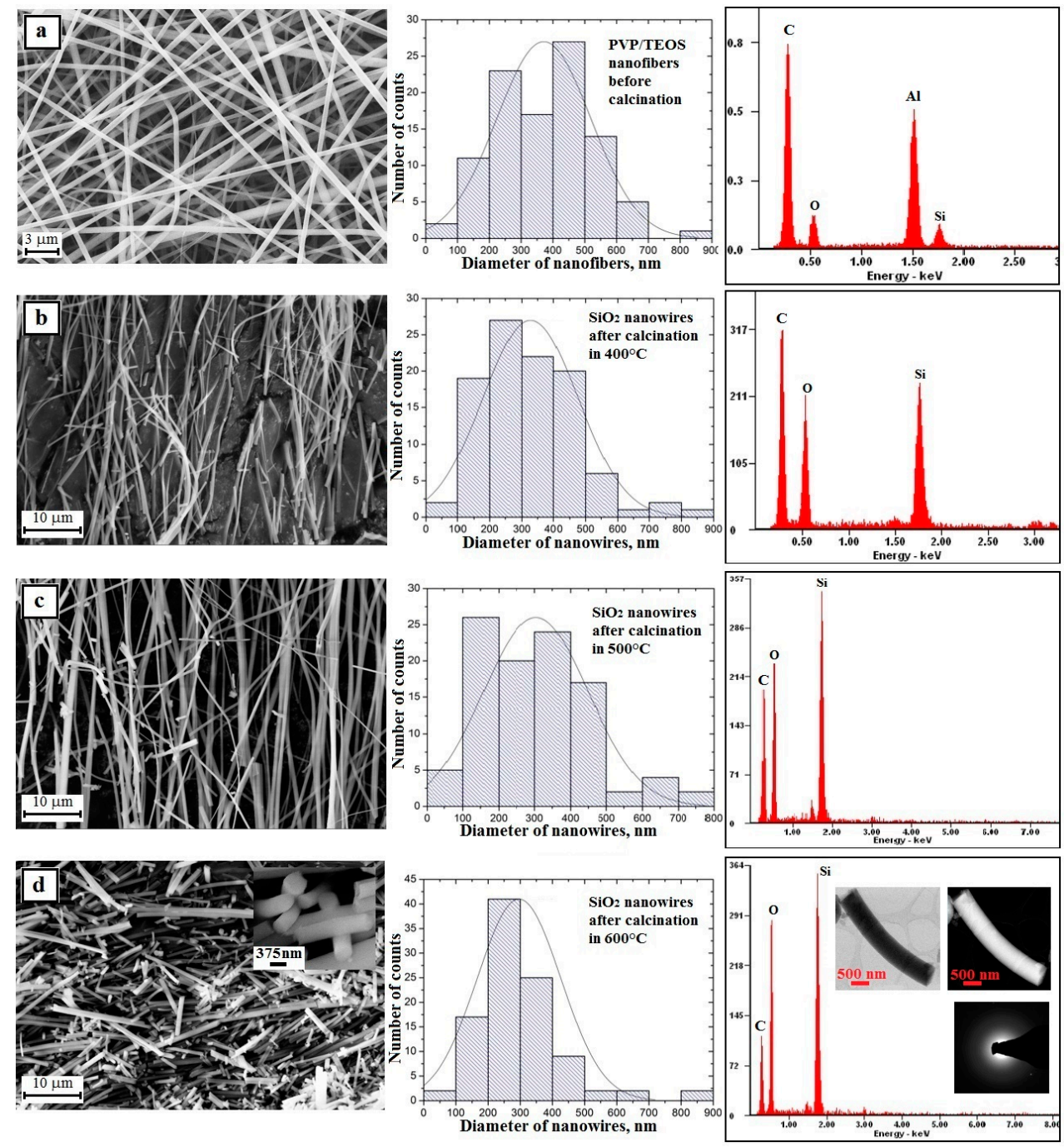

Figure 6. Left: SEM image of the topography on the surface of the formed fibrous composite mats, obtained nanowires; Middle: histograms presenting the distribution of hundredfold measurement of the diameter of randomly selected: (a) nanofibers obtained from PVP/TEOS/ $\mathrm{H}_{2} \mathrm{O} / \mathrm{AcOH} / \mathrm{EtOH}$ solution, (b-d) $\mathrm{SiO}_{2}$ nanowires after calcination in $400{ }^{\circ} \mathrm{C}, 500{ }^{\circ} \mathrm{C}$, and $600{ }^{\circ} \mathrm{C}$; Right: obtained EDS spectra (peaks of $\mathrm{Al}$ derive from the substrate on which nanofibers were deposited while $\mathrm{Au}$ and $\mathrm{Pd}$ derive from the conductive layer sputtered onto the produce nanostructures) from the entire area shown in the SEM images and TEM images for $\mathrm{SiO}_{2}$ nanowires obtained in $600{ }^{\circ} \mathrm{C}$ including an image in a light and dark area with diffraction image from single nanowires.

A hundred-fold measurement of the diameters of the obtained PVP/TNBT hybrid nanofibers showed that the measured diameters ranged from $50 \mathrm{~nm}$ to $1000 \mathrm{~nm}$ with the most frequent diameters ranging from $100 \mathrm{~nm}$ to $200 \mathrm{~nm}$, which accounted for $38 \%$ of all measured diameters for these samples where the average value of the nanofibers studied was $278 \mathrm{~nm}$ (Figure 8a-histogram).

Subjecting the obtained PVP/TNBT fibrous mat to a thermal treatment at temperatures of $400{ }^{\circ} \mathrm{C}, 500{ }^{\circ} \mathrm{C}$, and $600{ }^{\circ} \mathrm{C}$ allowed us to obtain, in each case, pure titanium oxide nanostructures (see Figure $6 \mathrm{~b}-\mathrm{d}$ ), which form a characteristic grid with characteristic knot-shaped connections and create a residue on the beads resulting from the precursor's hydrolysis and condensation. This was 
confirmed by the analysis of the EDS spectra obtained for these materials (Figure 8b-d-EDS spectra). In order to further describe the results of the analyses, we will define the obtained $\mathrm{TiO}_{2}$ nanostructures as nanowires and the description will concern agglomerates of particles produced as a result of the conducted calcination process excluding the agglomerates themselves.
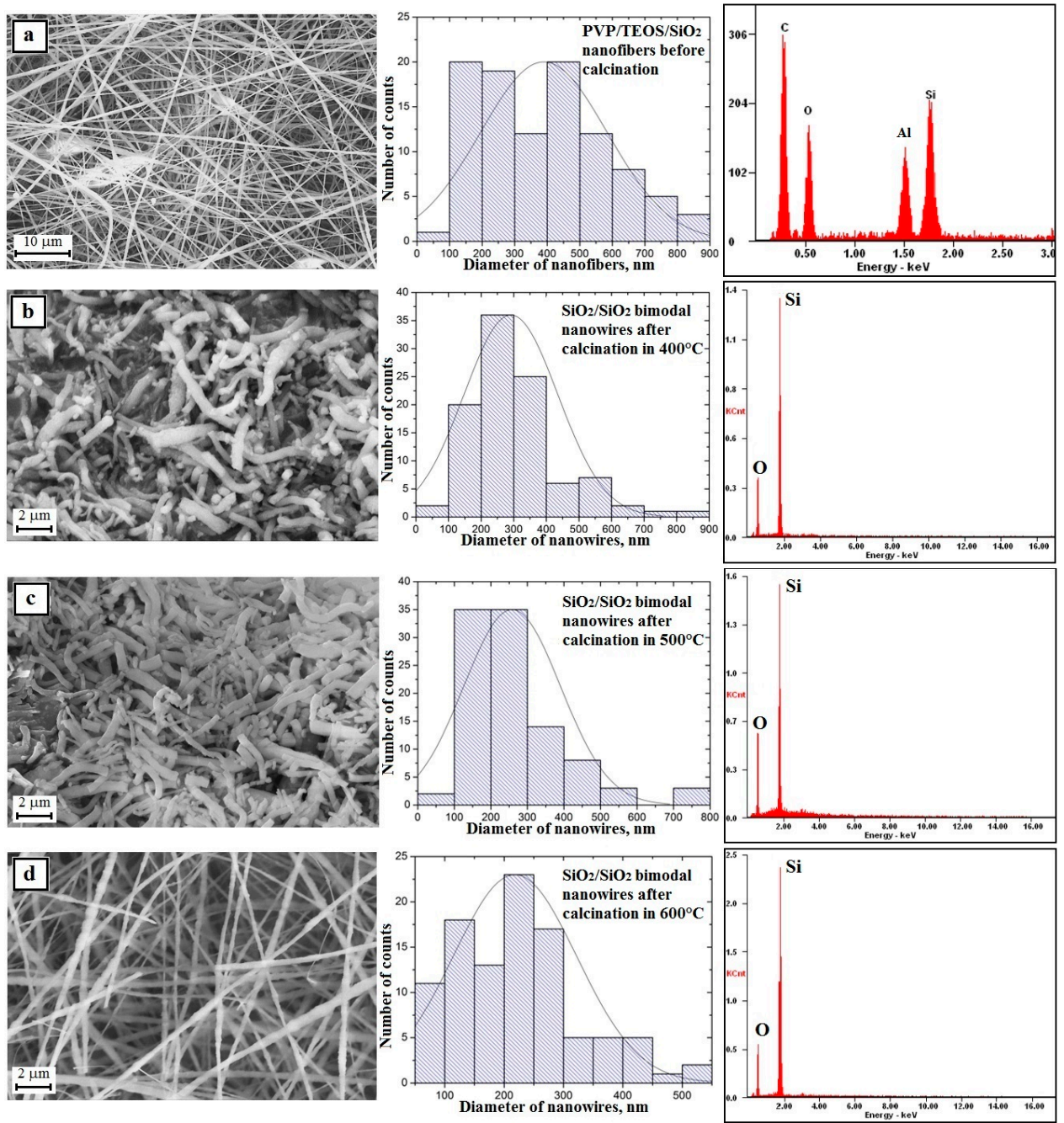

Figure 7. Left: SEM image of the topography on the surface of the formed fibrous composite mats, obtained nanowires; Middle: histograms presenting the distribution of hundredfold measurement of the diameter of randomly selected: (a) nanofibers obtained from PVP/TEOS $/ \mathrm{SiO}_{2} / \mathrm{H}_{2} \mathrm{O} / \mathrm{AcOH} / \mathrm{EtOH}$ solution, (b-d) bimodal $\mathrm{SiO}_{2} / \mathrm{SiO}_{2}$ nanowires after calcination in 400, 500 and $600{ }^{\circ} \mathrm{C}$; Right: obtained EDS spectra (peaks of $\mathrm{Al}$ derive from the substrate on which nanofibers were deposited while Au and Pd derive from the conductive layer sputtered onto the produce nanostructures) from the entire area shown in the SEM images.

Research on the morphology of the obtained $\mathrm{TiO}_{2}$ nanowires created using the SEM microscope showed that the obtained one-dimensional ceramic nanostructures were characterized by smaller diameters of individual nanowires and compared to hybrid fibers used as the starting material for their production. Calcination of fibrous PVP/TNBT mats at high temperatures for $3 \mathrm{~h}$ allowed the removal of the organic phase from the fibers and the formation of titanium oxide nanowires whose measured diameters ranged from $40 \mathrm{~nm}$ to $650 \mathrm{~nm}$ for a sample annealed at $400{ }^{\circ} \mathrm{C}$. Nanowires with diameters of $100-200 \mathrm{~nm}$ were the largest group and amounted to $28 \%$ (Figure $8 \mathrm{~b}-$ histogram). The measured diameters of the $\mathrm{TiO}_{2}$ nanowires obtained by calcination at $500{ }^{\circ} \mathrm{C}$ were in the range of 80 to $600 \mathrm{~nm}$. 
The largest group constituting 33\% of all nanowires of this sample was comprised of nanowires with diameters of 50-100 nm (Figure 7c-histogram). The smallest diameter values were recorded for titanium oxide nanowires resulting from the calcination process of PVP/TNBT hybrid nanofibres at $600{ }^{\circ} \mathrm{C}$. For this sample, the generated nanostructures were characterized by values of measured diameters in the range from 30 to $610 \mathrm{~nm}$ (Figure $8 \mathrm{~d}$-histogram). In addition, a hundred-fold measurement of randomly chosen nanowires of this sample showed that the largest group of $34 \%$ were one-dimensional structures with diameters ranging from $50 \mathrm{~nm}$ to $100 \mathrm{~nm}$. The analysis of the average values of diameters of the produced $\mathrm{TiO}_{2}$ nanowires, which were successively $214 \mathrm{~nm}, 159 \mathrm{~nm}$, and $153 \mathrm{~nm}$ after calcination at temperatures of $400{ }^{\circ} \mathrm{C}, 500{ }^{\circ} \mathrm{C}$, and $600{ }^{\circ} \mathrm{C}$, unambiguously shows a significant influence of temperature on the morphology of the manufactured one-dimensional titanium oxide nanostructures.
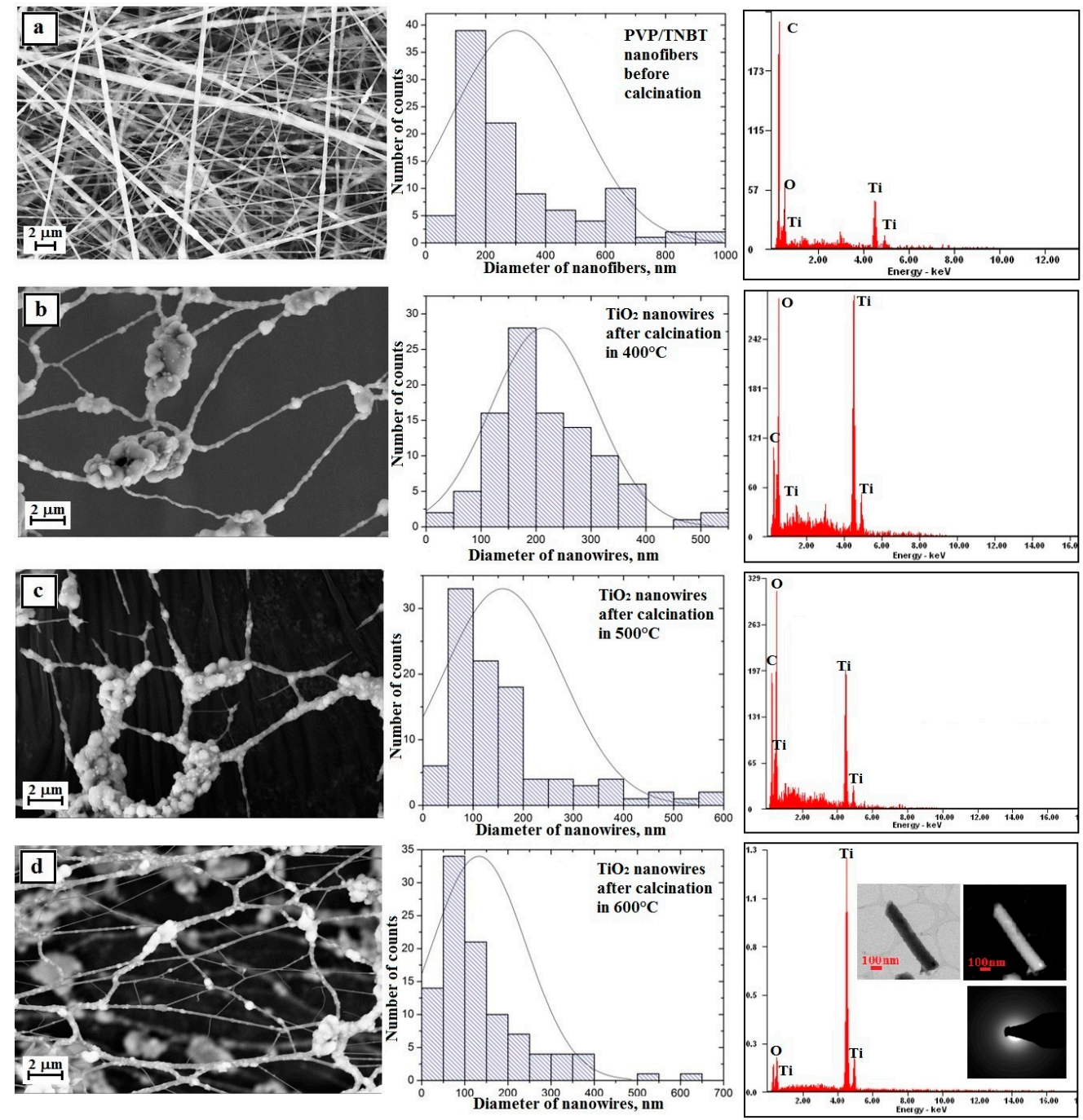

Figure 8. Left: SEM image of the topography on the surface of the formed fibrous composite mats, obtained nanowires; Middle: histograms presenting the distribution of hundredfold measurement of the diameter of randomly selected: (a) nanofibers obtained from PVP/TNBT/AcOH/EtOH solution, (b-d) $\mathrm{TiO}_{2}$ nanowires after calcination in $400{ }^{\circ} \mathrm{C}, 500{ }^{\circ} \mathrm{C}$, and $600{ }^{\circ} \mathrm{C}$; Right: obtained EDS spectra (peaks of $\mathrm{Al}$ derive from the substrate on which nanofibers were deposited while $\mathrm{Au}$ and $\mathrm{Pd}$ derive from the conductive layer sputtered onto the produce nanostructures) from the entire area shown in the SEM images and TEM images for $\mathrm{TiO}_{2}$ nanowires obtained in $600{ }^{\circ} \mathrm{C}$ an image in a light and dark area with diffraction image from single nanowires. 
The analysis of the SEM image of the surface topography of a fibrous mat made of PVP/TNBT hybrid composite nanofibers containing titanium dioxide nanoparticles with a $25 \%$ concentration by mass indicates that, unlike nanofibers made from a solution containing no $\mathrm{TiO}_{2}$ nanoparticles, the obtained one-dimensional $\mathrm{PVP} / \mathrm{TNBT} / \mathrm{TiO}_{2}$ structures were free of structural defects in the form of visible nanoparticle agglomerates of the used nano filler (see Figure 9a).
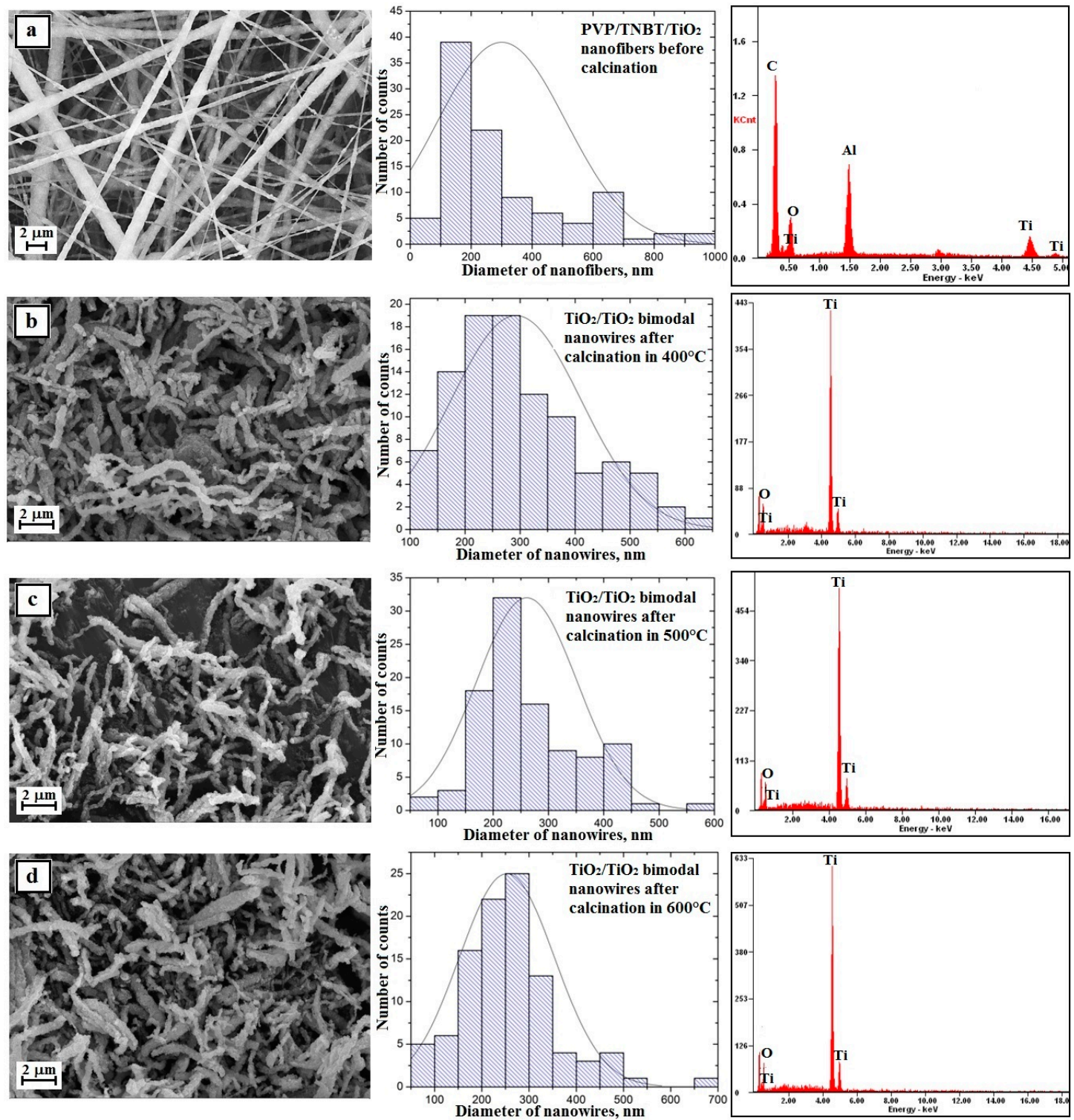

Figure 9. Left: SEM image of the topography on the surface of the formed fibrous composite mats and obtained nanowires; Middle: histograms presenting the distribution of hundredfold measurement of the diameter of randomly selected: (a) nanofibers obtained from $\mathrm{PVP} / \mathrm{TNBT} / \mathrm{TiO}_{2} / \mathrm{AcOH} / \mathrm{EtOH}$ solution, (b-d) bimodal $\mathrm{TiO}_{2} / \mathrm{TiO}_{2}$ nanowires after calcination in $400{ }^{\circ} \mathrm{C}, 500{ }^{\circ} \mathrm{C}$, and $600{ }^{\circ} \mathrm{C}$; Right: obtained EDS spectra (peaks of $\mathrm{Al}$ derive from the substrate on which nanofibres were deposited, while $\mathrm{Au}$ and Pd derive from the conductive layer sputtered onto the produce nanostructures) from the entire area shown in the SEM images and TEM images for $\mathrm{TiO}_{2}$ nanowires obtained in $600{ }^{\circ} \mathrm{C}$ an image in a light and dark area with diffraction image from single nanowires.

Structural defects in the form of beads resulting from the phenomenon of hydrolysis and condensation of molecules of the used TNBT precursor were also not registered while the average diameter value of the obtained nanofibers was $300 \mathrm{~nm}$, which clearly demonstrates the positive effect 
of the presence of nanoparticles of titanium oxide used in the spinning solution on the morphology and structure of the obtained hybrid composite nanofibers of $\mathrm{PVP} / \mathrm{TNBT} / \mathrm{TiO}_{2}$.

Subjecting the obtained $\mathrm{PVP} / \mathrm{TEOS} / \mathrm{TiO}_{2}$ fibrous mats to the calcination process at temperatures of $400{ }^{\circ} \mathrm{C}, 500{ }^{\circ} \mathrm{C}$, and $600{ }^{\circ} \mathrm{C}$ allowed to obtain one-dimensional bimodal nanostructures of pure titanium oxide (Figure $9 \mathrm{~b}-\mathrm{d}-\mathrm{EDS}$ spectra). Bimodal $\mathrm{TiO}_{2} / \mathrm{TiO}_{2}$ nanowires obtained by the calcination of a fibrous mat at $400{ }^{\circ} \mathrm{C}$ were characterized by diameters ranging from $100 \mathrm{~nm}$ to $700 \mathrm{~nm}$. The most numerous group of $38 \%$ consisted of nanowires with diameters ranging from $200-300 \mathrm{~nm}$ (see Figure 9b). An increase in the calcination temperature to $500{ }^{\circ} \mathrm{C}$ caused a slight change in the recorded diameters of the obtained nanowires. In this case, the diameters were in the range from $90 \mathrm{~nm}$ to $700 \mathrm{~nm}$ and the most numerous group of $32 \%$ consisted of $\mathrm{TiO}_{2} / \mathrm{TiO}_{2}$ nanowires with diameters in the range of 200-250 nm (see Figure 9c). The use of the highest calcination temperature of $600{ }^{\circ} \mathrm{C}$ resulted in similar results to those obtained after the calcination process of the hybrid nanofibrous $\mathrm{PVP} / \mathrm{TEOS} / \mathrm{TiO}_{2}$ mat at $500{ }^{\circ} \mathrm{C}$. The resulting bimodal $\mathrm{TiO}_{2} / \mathrm{TiO}_{2}$ nanowires were characterized by diameters ranging from $80 \mathrm{~nm}$ to $700 \mathrm{~nm}$ with the most frequently occurring diameters ranging from $250 \mathrm{~nm}$ to $300 \mathrm{~nm}$ (see Figure 9d). The analysis of the morphology of the produced bimodal $\mathrm{TiO}_{2}$ nanowires showed a decrease in the average diameters of one-dimensional nanostructures along with a temperature increase during the calcination process. The use of the calcination process for three hours at temperatures of $400{ }^{\circ} \mathrm{C}, 500{ }^{\circ} \mathrm{C}$, and $600{ }^{\circ} \mathrm{C}$, successively, contributed to the production of bimodal one-dimensional $\mathrm{TiO}_{2} / \mathrm{TiO}_{2}$ nanostructures with diameters of $293 \mathrm{~nm}, 261 \mathrm{~nm}$, and $253 \mathrm{~nm}$.

The comparison of the surface topography of the produced $\mathrm{TiO}_{2}$ nanowires and bimodal $\mathrm{TiO}_{2} / \mathrm{TiO}_{2}$ nanowires indicates a significant effect of the applied ceramic nanoparticles on the surface structure of the obtained one-dimensional nanostructures (see Figure 8). Regardless of the calcination temperature used, the surface area of the obtained one-dimensional bimodal titanium dioxide nanomaterials, compared to nanowires obtained from the PVP/TNBT/EtOH solution, was clearly uneven and was characterized by numerous "frayings". The mechanism of the occurrence of uneven, fuzzy surface of the produced bimodal $\mathrm{TiO}_{2} / \mathrm{TiO}_{2}$ nanostructures, which accompanied the share of $\mathrm{TiO}_{2}$ nanoparticles in the spinning solution, has a significant impact on the increase in the specific surface area of the obtained titanium oxide nanostructures. This results in a significant extension of the application possibilities of this type of materials or used devices built on the basis of $\mathrm{TiO}_{2}$ nanowires. Increasing the contact surface of the produced one-dimensional nanostructures of titanium oxide with catalysts will significantly affect the rate of photo catalysis, which is desirable in the case of self-cleaning surfaces. In addition, the use of $\mathrm{TiO}_{2}$ nanowires with the observed surface morphology may potentially result in an increase in the efficiency of the new generation of photovoltaic cells through the increase of the contact surface of semi-conductive bimodal, one-dimensional $\mathrm{TiO}_{2} / \mathrm{TiO}_{2}$ nanostructures with dye particles.

\subsection{Optical Investigations}

In order to analyze the optical properties of the produced one-dimensional, ceramic nanomaterials, the spectra of absorption in the function of wavelength obtained using a UV-Vis spectrometer were registered for all six groups of nanowires (see Figure 10a,b). The absorption spectra in the function of wavelength registered for $\mathrm{SiO}_{2}$ nanowires as well as for bimodal $\mathrm{SiO}_{2} / \mathrm{SiO}_{2}$ nanowires showed that the addition of silica nanoparticles to the spinning solution did not contribute to a change in the optical properties of the one-dimensional nanostructures of silicon oxide (see Figure 10a ,b). The absorption dependencies in the function of wavelength obtained for $\mathrm{SiO}_{2}$ nanowires and bimodal $\mathrm{SiO}_{2} / \mathrm{SiO}_{2}$ nanowires showed the presence of a sharp absorption edge for wavelengths of approximately $300 \mathrm{~nm}$ while the absorption maxima corresponded with wavelengths of approximately $250 \mathrm{~nm}$. 

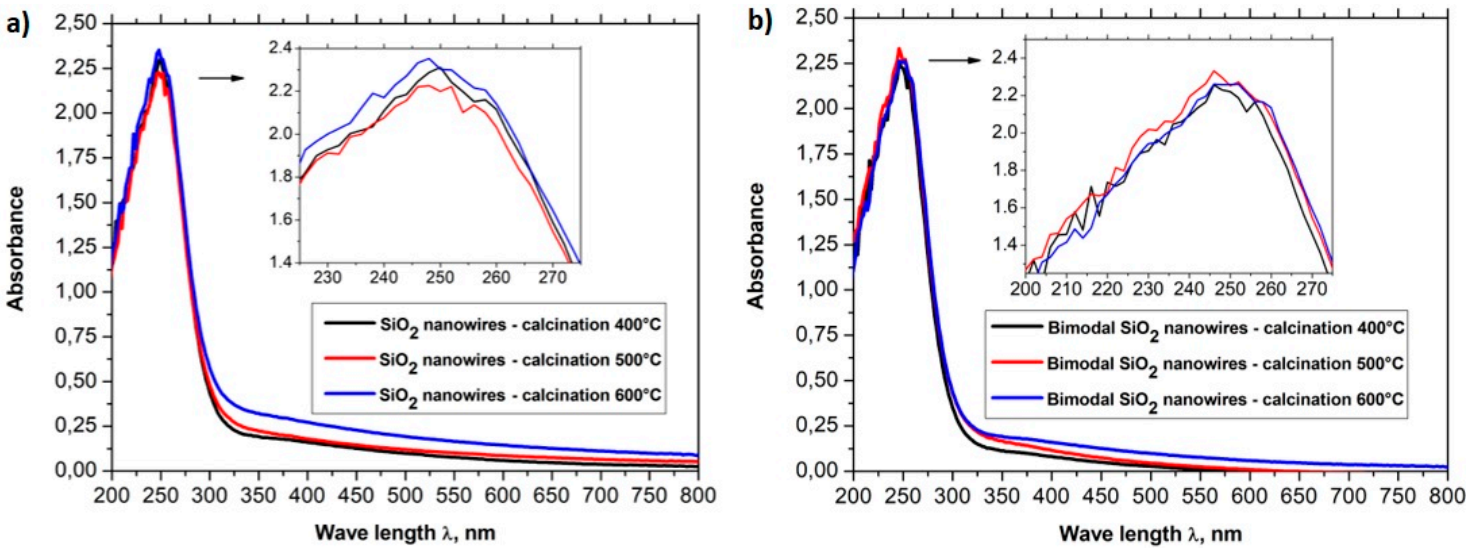

Figure 10. UV-Vis spectra obtained for (a) $\mathrm{SiO}_{2}$ nanowires and (b) bimodal $\mathrm{SiO}_{2}$ nanowires.

The spectral characteristics that were registered for one-dimensional nanowires of titanium oxide showed the presence of a sharp absorption edge in the region of close ultraviolet. The presence of the sharp absorption edge concerned wavelengths of approximately $325 \mathrm{~nm}$. Additionally, it was shown that with an increase of the temperature of calcination of hybrid PVP/TNBT nanofibers, which constitute the starting material for the production of one-dimensional nanostructures of titanium oxide, the obtained $\mathrm{TiO}_{2}$ nanowires were characterized by a constant maximum of absorption for wavelengths of $248 \mathrm{~nm}$ as well as a linear decrease of the level of absorption of electromagnetic radiation from 2.42 $\mathrm{nm}$ for nanowires obtained at a temperature of $400{ }^{\circ} \mathrm{C}$ to $2.26 \mathrm{~nm}$ for nanowires obtained during the process of calcination at a temperature of $600{ }^{\circ} \mathrm{C}$ (see Figure 10a).

For bimodal $\mathrm{TiO}_{2} / \mathrm{TiO}_{2}$ nanowires (see Figure $10 \mathrm{~b}$ ), the obtained spectrum showed the presence of strong absorption in the ultraviolet range where in the rage of close ultraviolet as well as in the rage of visible light, the level of absorption for bimodal nanostructures of titanium oxide obtained by using temperatures in the range of $400-600{ }^{\circ} \mathrm{C}$ during the calcination process, which reached higher values than those registered for nanowires of titanium oxide that did not contain $\mathrm{TiO}_{2}$ particles. In the rage of visible light, the level of absorption of electromagnetic radiation increased from a value of 0.5 to a value of approx. 1.1 while, in the range of close ultraviolet, the level of absorption for bimodal $\mathrm{TiO}_{2} / \mathrm{TiO}_{2}$ reached a value of 3.5. The results of the research on the effects of bimodal one-dimensional nanostructures of titanium oxide with electromagnetic radiation unambiguously point to the improved optical properties of such structures in comparison to conventional $\mathrm{TiO}_{2}$ nanowires. A more effective absorption of ultraviolet radiation can contribute to an increased speed of the photocatalytic reaction that can be of great significance in the case of $\mathrm{TiO}_{2}$, which is considered a material with increased photocatalytic properties and is used in such application as self-cleaning, superhydrophilic, antibacterial, antistatic, and deodorizing coatings. Moreover, this type of materials can constitute a more effective alternative for thin semi-conductive coatings currently used for the production of dye-sensitized solar cells due to a much larger specific surface area in relation to the homogeneous layers obtained when using the spin-coating process.

In order to analyze the optical properties of the produced single-dimensional ceramic nanomaterials, for all four groups of nanowires, the spectra of absorbance as a function of wavelength were obtained using a UV-Vis spectrometer. Based on the obtained dependences $A(\lambda)$ and the equations derived in the Theory section, the dependencies of the real $n^{\prime}(\lambda)$ and imaginary $k(\lambda)$ part of the refractive index, real and complex dielectric permittivity $\varepsilon_{r}(\lambda), \varepsilon_{i}(\lambda)$, and complex values of the refractive index, dielectric permittivity and energy gap width values for the produced ceramic $\mathrm{SiO}_{2}$, $\mathrm{TiO}_{2}$ and bimodal nanowires $\mathrm{SiO}_{2} / \mathrm{SiO}_{2}$, and $\mathrm{TiO}_{2} / \mathrm{TiO}_{2}$ (Figures 7-15) were obtained. 

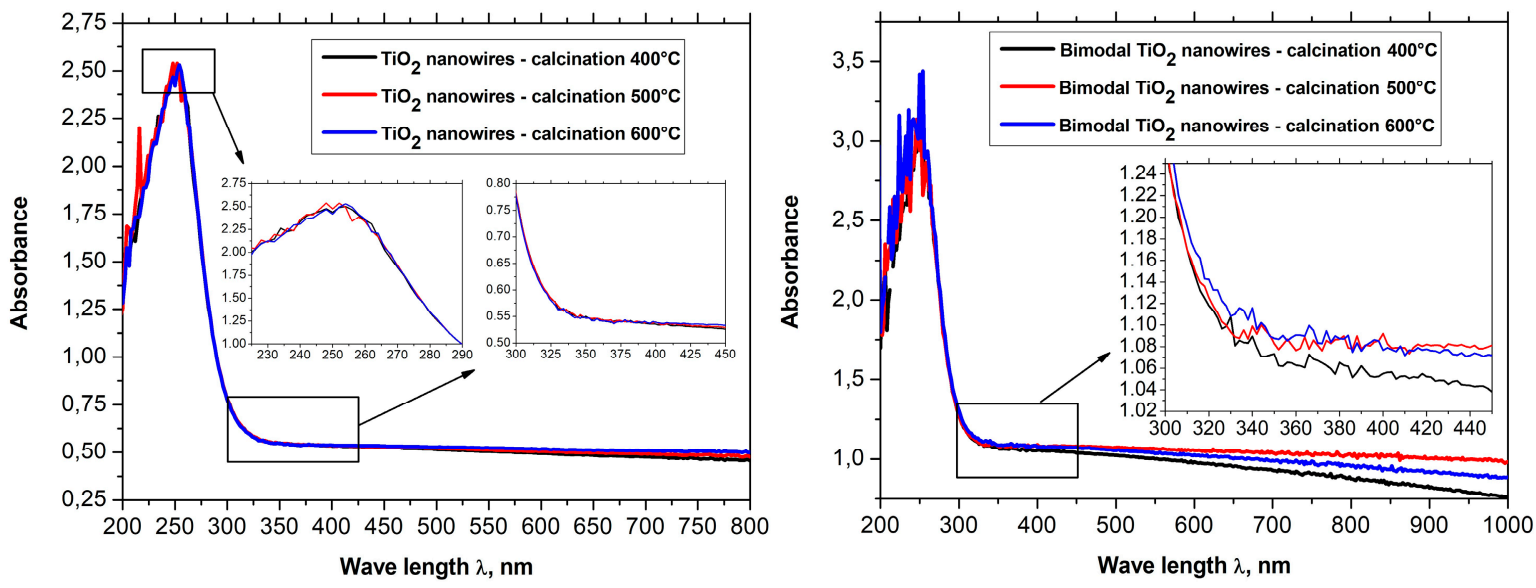

Figure 11. UV-Vis spectra obtained for (a) $\mathrm{TiO}_{2}$ nanowires and (b) bimodal $\mathrm{TiO}_{2}$ nanowires.
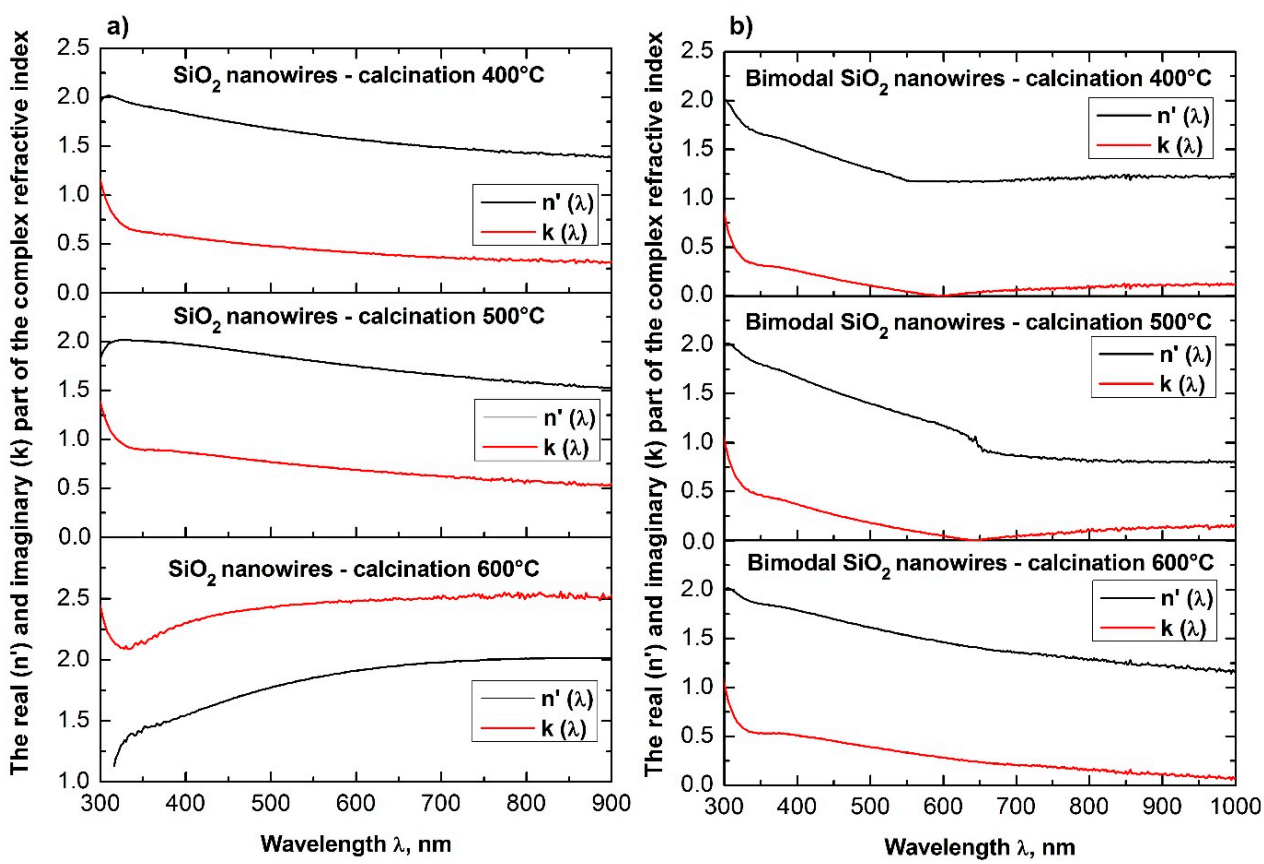

Figure 12. Dependences of the real $n^{\prime}(\lambda)$ (a) and imaginary $k(\lambda)$ parts (b) of the refractive index determined for the produces $\mathrm{SiO}_{2}$ ceramic nanowires and bimodal $\mathrm{SiO}_{2} / \mathrm{SiO}_{2}$ nanowires. 

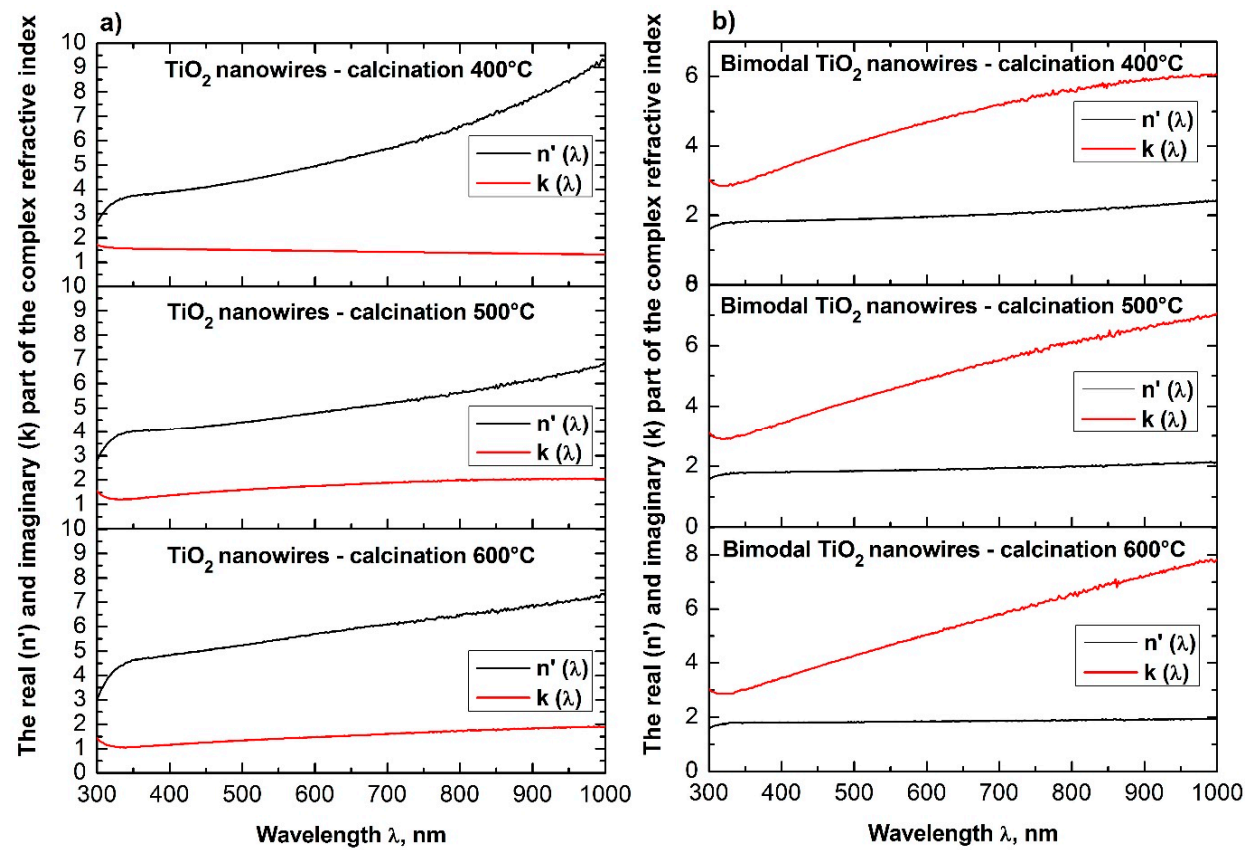

Figure 13. Dependences on the real $n^{\prime}(\lambda)$ (a) and imaginary $k(\lambda)$ parts (b) of the refractive index determined for the produced $\mathrm{TiO}_{2}$ ceramic nanowires and bimodal $\mathrm{TiO}_{2} / \mathrm{TiO}_{2}$ nanowires.
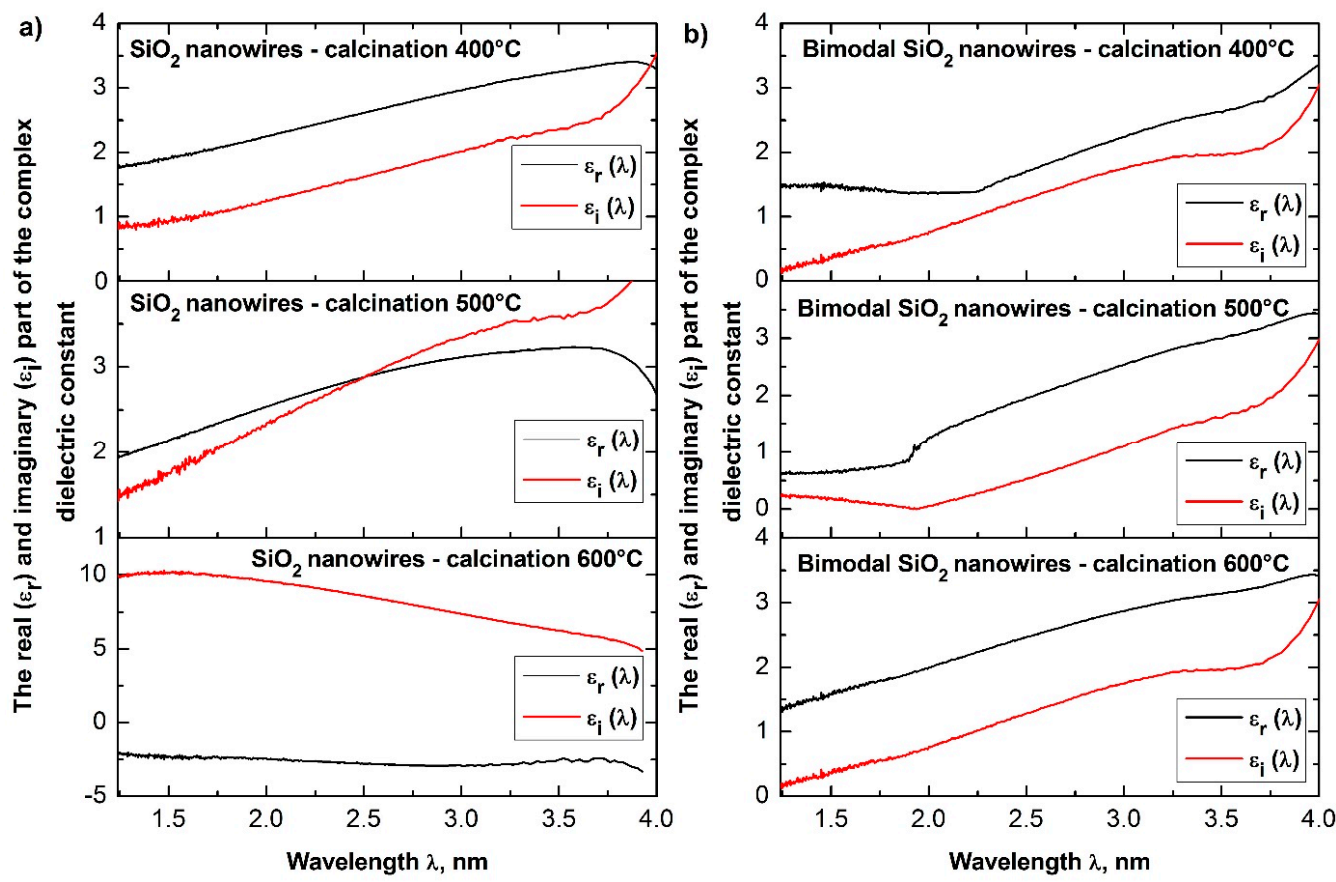

Figure 14. Dependences of the real $\varepsilon_{r}(\lambda)(\mathbf{a})$ and imaginary $\varepsilon_{i}(\lambda)$ parts $(\mathbf{b})$ of the dielectric constant for the produced $\mathrm{SiO}_{2}$ ceramic nanowires and bimodal $\mathrm{SiO}_{2} / \mathrm{SiO}_{2}$ nanowires. 

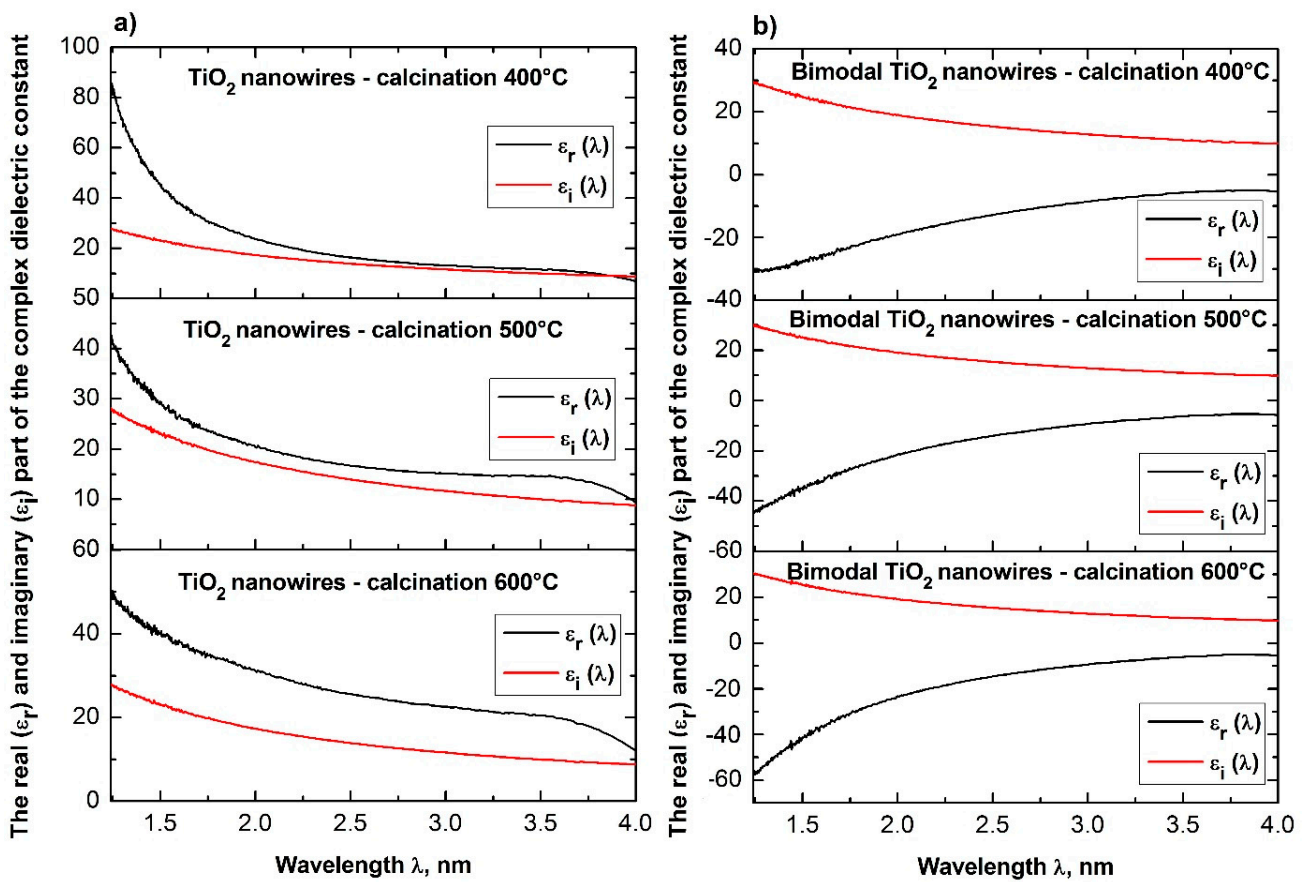

Figure 15. Dependences of the real $\varepsilon_{r}(\lambda)$ (a) and imaginary $\varepsilon_{i}(\lambda)$ parts (b) of the complex dielectric constant for the produced $\mathrm{TiO}_{2}$ ceramic nanowires and bimodal $\mathrm{TiO}_{2} / \mathrm{TiO}_{2}$ nanowires.

The analysis of the complex refractive index for the produced $\mathrm{SiO}_{2}$ ceramic nanowires indicates that subjecting the thin fibrous mat containing nanofibers obtained from the solution of $\mathrm{PVP} / \mathrm{TEOS} / \mathrm{AcOH} / \mathrm{EtOH}$ to the calcination process at $400^{\circ} \mathrm{C}$ for $3 \mathrm{~h}$ contributed to obtaining silicon oxide nanowires, which were characterized by the smallest determined value of the refractive index among all the produced and tested one-dimensional ceramic structures (see Table 1).

Table 1. Determined values of the complex refractive index, dielectric permittivity and energy gap width values obtained for the produced nanowires.

\begin{tabular}{|c|c|c|c|c|c|c|c|c|c|c|c|c|}
\hline \multirow{3}{*}{ Parameter } & \multicolumn{3}{|c|}{$\mathrm{SiO}_{2}$} & \multicolumn{3}{|c|}{$\mathrm{SiO}_{2} / \mathrm{SiO}_{2}$} & \multicolumn{3}{|c|}{$\mathrm{TiO}_{2}$} & \multicolumn{3}{|c|}{$\mathrm{TiO}_{2} / \mathrm{TiO}_{2}$} \\
\hline & \multicolumn{3}{|c|}{$\begin{array}{c}\text { Calcination } \\
\text { Temperature }\left[{ }^{\circ} \mathrm{C}\right]\end{array}$} & \multicolumn{3}{|c|}{$\begin{array}{c}\text { Calcination } \\
\text { Temperature }\left[{ }^{\circ} \mathrm{C}\right]\end{array}$} & \multicolumn{3}{|c|}{$\begin{array}{c}\text { Calcination } \\
\text { Temperature }\left[{ }^{\circ} \mathrm{C}\right]\end{array}$} & \multicolumn{3}{|c|}{$\begin{array}{c}\text { Calcination } \\
\text { Temperature }\left[{ }^{\circ} \mathrm{C}\right]\end{array}$} \\
\hline & 400 & 500 & 600 & 400 & 500 & 600 & 400 & 500 & 600 & 400 & 500 & 600 \\
\hline$n$ & 1.46 & 1.48 & 1.60 & 1.60 & 1.71 & 1.73 & 2.62 & 2.57 & 2.49 & 2.49 & 2.52 & 2.57 \\
\hline$\varepsilon$ & 2.13 & 2.19 & 2.56 & 2.56 & 2.92 & 2.99 & 6.86 & 6.60 & 6.20 & 6.20 & 6.35 & 6.60 \\
\hline$E_{g}[\mathrm{eV}]$ & 4.19 & 4.31 & 4.40 & 4.50 & 4.39 & 4.29 & 3.73 & 3.83 & 3.88 & 3.58 & 3.42 & 3.30 \\
\hline
\end{tabular}

This value corresponds to the refractive index for $\mathrm{SiO}_{2}$ presented in [45], which clearly indicates the accurateness both of the process of manufacturing silicon oxide nanowires and the validity of the carried out of the theoretical considerations and experimental analyses.

Annealing of hybrid nanofibers of PVP/TEOS at $500{ }^{\circ} \mathrm{C}$ increased the obtained value of the refractive index of 0.02 relative to the refractive index of $\mathrm{SiO}_{2}$ nanowires received at the lowest used temperature.

The use of the highest temperature during the calcination process of $600{ }^{\circ} \mathrm{C}$ resulted in obtaining silicon oxide nanowires characterized by the highest optical density of which refractive indices reached the value of 1.60. The obtained value of complex refractive index of 1.46 for $\mathrm{SiO}_{2}$ ceramic nanowires produced during the calcination of hybrid PVP/TEOS nanofibers at a temperature of $400{ }^{\circ} \mathrm{C}$ corresponds to the refractive index for silicon oxide presented by Malitson in Reference [45], which 
clearly indicates the accuracy of the manufacturing process of silicon oxide nanowires and the validity of the theoretical considerations and experimental analyses.

Furthermore, the increase of the complex refractive index values of the $\mathrm{SiO}_{2}$ nanowires obtained at different calcination temperatures $\left(400^{\circ} \mathrm{C}\right.$ to $\left.600^{\circ} \mathrm{C}\right)$ is probably related to the morphology of the tested ceramic nanostructures.

The analyses indicate the influence of the diameter of the tested silica nanowires on their optical properties. During the acquisition process of $\mathrm{SiO}_{2}$ nanowires characterized by the same structure and chemical composition, it is possible to manipulate the optical density values of the used ceramic nanostructures by changing the diameters of individual nanowires.

The addition of silicon oxide nano powder to the PVP/TEOS/AcOH/EtOH spinning solution allowed to obtain bimodal, amorphous one-dimensional $\mathrm{SiO}_{2}$ nanostructures that were characterized by higher optical densities were compared to the optical density of $\mathrm{SiO}_{2}$ nanowires obtained from a solution containing no nanoparticles in the form of silica nanoparticles. Bimodal $\mathrm{SiO}_{2} / \mathrm{SiO}_{2}$ nanowires obtained by the calcination of composite PVP $/ \mathrm{TEOS} / \mathrm{SiO}_{2}$ nanofibers at $400{ }^{\circ} \mathrm{C}$ for $3 \mathrm{~h}$ were characterized by the same values of complex refractive index light of 1.60 , which had pure silicon oxide nanowires produced at a calcination temperature of $600{ }^{\circ} \mathrm{C}$.

The application of higher temperatures during the calcination process of $\mathrm{PVP} / \mathrm{TEOS} / \mathrm{SiO}_{2}$ composite nanofibers allowed to maintain one-dimensional $\mathrm{SiO}_{2} / \mathrm{SiO}_{2}$ ceramic nanostructures with complex refractive index values of 1.71 in the case of nanowires obtained by calcination at $500{ }^{\circ} \mathrm{C}$ as well as 1.73 for nanowires obtained at $600{ }^{\circ} \mathrm{C}$.

This fact demonstrates the significant influence of the presence of a nano filler on the optical properties of the produced bimodal, monomaterial ceramic nanomaterials, and the potential to control their properties by changing the mass concentration of silica nanoparticles in the spinning solution.

The analysis of the optical properties of one-dimensional titanium oxide nanostructures obtained due to calcination of thin fibrous PVP/TNBT hybrid mats showed a decrease in the value of the refractive index of $\mathrm{TiO}_{2}$ ceramic nanowires accompanying a temperature increase during the calcination process (see Table 1). Titanium oxide nanowires obtained as a result of calcination at $400{ }^{\circ} \mathrm{C}$ were characterized by the highest optical density of all the obtained one-dimensional $\mathrm{TiO}_{2}$ nanostructures. In this case, the maximum refractive index amount to 2.62. The application of calcination temperatures of $500{ }^{\circ} \mathrm{C}$ enabled the formation of nanowires of titanium oxide with a refractive index of 2.57 . The use of a calcination temperature of $600{ }^{\circ} \mathrm{C}$ allowed to obtain $\mathrm{TiO}_{2}$ nanowires with the lowest registered optical density-the value of their complex refractive index was 2.49. The obtained results of the complex refractive index of the produced $\mathrm{TiO}_{2}$ ceramic nanowires coincide with the results presented in References [46-49], which confirm the correctness of the theoretical and experimental analyses.

Bimodal $\mathrm{TiO}_{2} / \mathrm{TiO}_{2}$ nanowires obtained by the calcination of composite PVP/TNBT nanofibers containing $25 \%$ (wt \%) of titanium oxide nanoparticles showed an opposite trend in the range of recorded electromagnetic radiation, which was compared to pure one-dimensional $\mathrm{TiO}_{2}$ nanostructures. The optical density of the obtained bimodal nanowires of titanium oxide increased as a result of the higher temperature of calcination. Bimodal $\mathrm{TiO}_{2} / \mathrm{TiO}_{2}$ nanostructures obtained at $400{ }^{\circ} \mathrm{C}$ were characterized by the same value of complex refractive index as $\mathrm{TiO}_{2}$ nanowires obtained at $600{ }^{\circ} \mathrm{C}$. A further increase in temperature to $500{ }^{\circ} \mathrm{C}$ and $600^{\circ} \mathrm{C}$ during the calcinations process of the composite $\mathrm{PVP} / \mathrm{TNBT} / \mathrm{TiO}_{2}$ nanofibers resulted in obtaining one-dimensional bimodal $\mathrm{TiO}_{2} / \mathrm{TiO}_{2}$ nanostructures with n coefficients of 2.52 and 2.57, respectively. This phenomenon is probably due to the phase composition of the applied titanium oxide nano powder containing both the rutile phase and the anatase phase.

The dependence of dielectric permeability as a function of the radiation frequency incident on the sample can be presented in the following form [50].

$$
\varepsilon=1+\frac{\mu e^{2}}{m \varepsilon_{0}}\left[\frac{\omega_{0}^{2}-\omega^{2}}{\left(\omega_{0}^{2}-\omega^{2}\right)^{2}+\gamma^{2} \omega^{2}}-i \frac{\gamma \omega}{\left(\omega_{0}^{2}-\omega^{2}\right)^{2}+\gamma^{2} \omega^{2}}\right]
$$


where $\mu$ is the concentration of atoms in the sample, $e$ and $m$ is the charge and mass of the electron, $\varepsilon_{0}$ is the electric permeability of the vacuum, $\gamma$ is the damping factor, and $\omega_{0}$ and $\omega$ are the frequencies of electrons, own vibrations, and radiation. From the above Equation (19), it follows that the dielectric constant is a complex value while its real and imaginary part can be written as the equations below.

$$
\begin{gathered}
\varepsilon^{\prime}=1+\frac{n e^{2}}{m \varepsilon_{0}} \frac{\omega_{0}^{2}-\omega^{2}}{\left(\omega_{0}^{2}-\omega^{2}\right)^{2}+\gamma^{2} \omega^{2}} \\
\varepsilon^{\prime \prime}=\frac{n e^{2}}{m \varepsilon_{0}} \frac{\omega_{0}^{2}-\omega^{2}}{\left(\omega_{0}^{2}-\omega^{2}\right)^{2}+\gamma^{2} \omega^{2}}
\end{gathered}
$$

Using the relation binding the index of refraction and the dielectric constant (9), the expressions on the real and imaginary part of optical permeability take the form below [50].

$$
\begin{aligned}
n^{\prime} & =\left\{\frac{1}{2}\left[\varepsilon^{\prime}+\left(\varepsilon \prime^{2}+\varepsilon \prime^{\prime}\right)\right]^{\frac{1}{2}}\right\}^{\frac{1}{2}} \\
n^{\prime \prime} & =\left\{\frac{1}{2}\left[-\varepsilon^{\prime}+\left(\varepsilon \prime^{2}+\varepsilon \prime^{2}\right)\right]^{\frac{1}{2}}\right\}^{\frac{1}{2}}
\end{aligned}
$$

The above equations show that with the increase of the refractive index of the tested medium, its dielectric permittivity increases. The analyses of the determined complex dielectric permittivity values of the produced ceramic nanowires of $\mathrm{SiO}_{2}$ and $\mathrm{TiO}_{2}$ as well as bimodal nanowires of $\mathrm{SiO}_{2} / \mathrm{SiO}_{2}$ and $\mathrm{TiO}_{2} / \mathrm{TiO}_{2}$ (see Table 1), which were conducted on the basis of the presented theoretical considerations and recorded spectra of absorbance as a function of the wavelength and coincide with the theoretical assumptions resulting from the dependence $n=\varepsilon^{1 / 2}$.

The analysis of the width of energy gaps in the studied amorphous ceramic nanowires unambiguously indicated a significant influence of the applied temperature during the calcination process and the presence of nanoparticles of the nano-filler in the obtained composites on the energy barrier between the conduction band and the valence band of the studied nanomaterials (see Table 1). The use of a temperature in the range of $400{ }^{\circ} \mathrm{C}$ to $600{ }^{\circ} \mathrm{C}$ during the annealing of hybrid PVP/TEOS nanofiber resulted in the formation of $\mathrm{SiO}_{2}$ nanowires characterized by values of the energy gap of $4.19,4.31$, and $4.40 \mathrm{eV}$, respectively. The $25 \%$ mass presence of silica nanoparticles in the spinning solution resulted in the opposite tendency of changing the values of the energy band gaps characteristic for bimodal $\mathrm{SiO}_{2} / \mathrm{SiO}_{2}$ nanowires, which resulted from the use of higher temperatures during the calcination process. In this case, the ever-higher temperature of composite $\mathrm{PVP} / \mathrm{TEOS} / \mathrm{SiO}_{2}$ nanofibers heating contributed to a decrease in the determined values of energy band gaps from $5.5 \mathrm{eV}$ to $4.29 \mathrm{eV}$. The tendency of decreasing values of the indicated energy gaps, which accompanies the increase of temperature during the calcination process, is in accordance with the results presented in papers on semi-conductive ceramic nanowires $[51,52]$ in which the same calcination temperatures of $400{ }^{\circ} \mathrm{C}$, $500{ }^{\circ} \mathrm{C}$, and $600{ }^{\circ} \mathrm{C}$ were applied in order to obtain ceramic nanostructures. A decrease of the values of the indicated energy gaps, which accompanies the use of increasing calcination temperatures, most likely results from the morphology of the obtained nanostructures. It can be assumed that the use of increasing calcination temperatures of the produced bimodal $\mathrm{SiO}_{2}$ nanowires cause a decrease of the obtained nanostructures and is associated with obtaining nanomaterials with decreasing values of the energy gap.

In addition, the calcination processes applied to hybrid fibrous PVP/TEOS mats and hybrid composite fibrous PVP/TEOS mats containing $\mathrm{SiO}_{2}$ nanoparticles resulted in the formation of $\mathrm{SiO}_{2}$ nanowires obtained by the sol-gel and electrospinning processes from the solution, which causes the formation of $\mathrm{SiO}_{2}$ nanowires with energy band gaps values ranging from $4.19 \mathrm{eV}$ to $4.5 \mathrm{eV}$, which is more than twice as good as the currently obtained amorphous silica structures [53]. 
The experimentally determined values of energy breaks in the produced $\mathrm{SiO}_{2}$ nanowires clearly indicate a broad spectrum of future applications including the electronics industry for building computer chips and solar batteries [54].

Similar relationships between the applied temperature and the presence of nanoparticles in the spinning solution were recorded for ceramic $\mathrm{TiO}_{2}$ nanowires and bimodal $\mathrm{TiO}_{2} / \mathrm{TiO}_{2}$ nanowires. In this case, similarly as in the case of bimodal nanowires of silicon oxide, the addition of nanoparticles to the spinning solution resulted in obtaining bimodal $\mathrm{TiO}_{2} / \mathrm{TiO}_{2}$ nanowires of which values of energy gap decreased when using increasing temperatures during the calcination process of composite fibers. The decrease of the indicated values of the energy gap for bimodal nanowires of titanium oxide most likely results from the decrease of the diameters of those structures, which can be observed when applying increasing annealing temperatures. The obtained values of energy breaks oscillating around $3.7 \mathrm{eV}$ can be caused by direct electron transitions from the valence band to the conduction band where the smallest determined $E_{g}$ value of $3.30 \mathrm{eV}$ corresponds to the intermediate electron transitions between the energy bands.

\section{Conclusions}

Using the sol-gel and electrospinning method, the aim of this work was to create and examine the morphology, structure, and optical properties of four types of one-dimensional ceramic nanostructures, which included $\mathrm{TiO}_{2}$ nanowires, $\mathrm{SiO}_{2}$ nanowires, and bimodal $\mathrm{TiO}_{2}$ nanowires filled with $\mathrm{TiO}_{2}$ nanoparticles and bimodal $\mathrm{SiO}_{2}$ nanowires filled with $\mathrm{SiO}_{2}$ nanoparticles. Particularly noteworthy is the fact that the author presented a method of obtaining composite nanofibers without structural defects constituting the starting material for the production of bimodal ceramic nanowires containing nano-fillers in the form of ceramic nanoparticles with mass concentration relative to the polymer mass of up to $25 \%$. It has been found that the use of nanoparticles with such a mass concentration at the stage of the spinning solution preparation allows to obtain bimodal nanowires with a much larger specific surface area than their nanofiller-free counterparts resulting from several times smaller diameters of individual nanostructures. In addition, it was shown that the use of nano-fillers in the form of nanoparticles of the same phase, which was the matrix of each type of nanowires and different calcination temperatures in the range $400-600{ }^{\circ} \mathrm{C}$, has a significant effect on the optical properties of the obtained one-dimensional ceramic nanostructures that were in the ranges 1.46-2.62 for a complex refractive index, 2.13-6.86 for combined dielectric permeability, and 3.3-4.5 eV for the energy gap width. The presented results of the research on innovative bimodal one-dimensional nanostructures unambiguously indicate the potential for controlling both the morphology and the optical properties of the obtained nanomaterials, which increase the scope of their application capabilities.

Acknowledgments: The research presented in this article was financed by the National Science Centre, Poland, based on the decision number 2014/15/B/ST8/04767. The publication is supported under the rector's professorial grant. Silesian University of Technology, 10/010/RGP17/0182.

Author Contributions: Tomasz Tański conceived and designed the experiments; performed, analyzed the data and described the TEM, SEM and EDS experiments, and selected UV-Vis results. Wiktor Matysiak performed, analyzed the data and described the UV-Vis and FTIR experiments.

Conflicts of Interest: The authors declare no conflict of interest.

\section{References}

1. Šutka, A.; Leinberg, S.; Kisand, V.; Saal, K.; Lõhmus, R.; Joost, U.; Timusk, M. Electro-optics of electrospun $\mathrm{TiO}_{2}$ anatase submicron wire based dipole particle suspension device. Opt. Mater. 2014, 37, 740-744. [CrossRef]

2. Choi, D.Y.; Hwang, C.H.; Lee, J.W.; Lee, I.H.; Oh, I.H.; Park, J.Y. Characterization of $\mathrm{TiO}_{2}$ fibers by combined electrospinning method and hydrothermal reaction. Mater. Lett. 2013, 106, 41-44. [CrossRef] 
3. Choi, K.I.; Lee, S.H.; Park, J.Y.; Choi, D.Y.; Hwang, C.H.; Lee, I.H.; Chang, M.H. Fabrication and characterization of hollow $\mathrm{TiO}_{2}$ fibers by microemulsion electrospinning for photocatalytic reactions. Mater. Lett. 2013, 112, 113-116. [CrossRef]

4. Memarian, F.; Latifi, M. $\mathrm{TiO}_{2}$ nanofiber yarns: A prospective candidate as a photocatalyst. J. Ind. Eng. Chem. 2015, 23, 182-187. [CrossRef]

5. Li, Y.; Ye, C.; Fang, X.; Yang, L.; Xiao, Y.; Zhang, L. Fabrication and photoluminescence of $\mathrm{SiO}_{2}$-sheathed semiconducting nanowires: The case of $\mathrm{ZnS} / \mathrm{SiO}_{2}$. Nanotechnology 2005, 16, 501. [CrossRef]

6. Huey, E.; Krishnan, S.; Arya, S.K.; Dey, A.; Bhansali, S. Optimized growth and integration of silica nanowires into interdigitated microelectrode structures for biosensing. Sens. Actuators B Chem. 2012, 175, 29-33. [CrossRef]

7. Meng, L.Y.; Han, S.; Jiang, N.; Meng, W. Study on superhydrophobic surfaces of octanol grafted electrospun silica nanofibers. Mater. Chem. Phys. 2014, 148, 798-802. [CrossRef]

8. Batool, S.S.; Imran, Z.; Israr-Qadir, M.; Jamil-Rana, S.; Usman, M.; Jamil, H.; Willander, M. Silica nanofibers based impedance type humidity detector prepared on glass substrate. Vacuum 2013, 87, 1-6. [CrossRef]

9. Arbiol, J.; Xiong, Q. Semiconductor Nanowires: Materials, Synthesis, Characterization and Applications, 1st ed.; Woodhead Publishing: Cambridge, UK, 2015; ISBN 9781782422532.

10. Du, J.; Li, X.; Li, K.; Gu, X.; Qi, W.; Zhang, K. High hydrophilic Si-doped $\mathrm{TiO}_{2}$ nanowires by chemical vapour deposition. J. Alloys Compd. 2016, 687, 893-897. [CrossRef]

11. Sadeghzadeh-Attar, A. Structural and optical characteristic of single crystal rutile-titania nanowire arrays prepared in alumina membranes. Mater. Chem. Phys. 2016, 182, 148-154. [CrossRef]

12. Jian, H.; Dayan, M.; Kewei, X. Growth and morphology modulation of needle-like silicon nanowires for SERS application. Rare Met. Mater. Eng. 2015, 44, 2692-2697. [CrossRef]

13. Li, H.; Guan, L.; Xu, Z.; Zhao, Y.; Sun, J.; Wu, J.; Xu, N. Synthesis and characterization of amorphous $\mathrm{SiO}_{2}$ nanowires via pulsed laser deposition accompanied by $\mathrm{N}_{2}$ annealing. Appl. Surf. Sci. 2016, 389, 705-712. [CrossRef]

14. Lee, K.H.; Yang, H.S.; Baik, K.H.; Bang, J.; Vanfleet, R.R.; Sigmund, W. Direct growth of amorphous silica nanowires by solid state transformation of $\mathrm{SiO}_{2}$ films. Chem. Phys. Lett. 2016, 383, 380-384. [CrossRef]

15. Park, S.; Heo, J.; Kim, H.J. A novel route to the synthesis of silica nanowires without a metal catalyst at room temperature by chemical vapour deposition. Nano Lett. 2011, 11, 740-745. [CrossRef] [PubMed]

16. Tong, H.; Tao, X.; Wu, D.; Zhang, X.; Li, D.; Zhang, L. Preparation and characterization of doped $\mathrm{TiO}_{2}$ nanofibers by coaxial electrospining combined with sol-gel process. J. Alloys Compd. 2014, 586, 274-278. [CrossRef]

17. Lee, J.S.; Lee, Y.I.; Song, H.; Jang, D.H.; Choa, Y.H. Synthesis and characterization of $\mathrm{TiO}_{2}$ nanowires with controlled porosity and microstructure using electrospinning method. Curr. Appl. Phys. 2011, 11, 210-214. [CrossRef]

18. Qin, N.; Xiong, J.; Liang, R.; Liu, Y.; Zhang, S.; Li, Y.; Wu, L. Highly efficient photocatalytic $\mathrm{H}_{2}$ evolution over $\mathrm{MoS}_{2} / \mathrm{CdS}-\mathrm{TiO}_{2}$ nanofibers prepared by an electrospinning mediated photodeposition method. Appl. Catal. B Environ. 2017, 202, 374-380. [CrossRef]

19. Li, S.; Dong, Y.; Guo, M. Photocatalytic activity of different morphologies $\mathrm{TiO}_{2}$ nanofibers. Appl. Surf. Sci. 2012, 258, 8015-8018. [CrossRef]

20. Mukhlish, M.Z.B.; Horie, Y.; Higashi, K.; Ichigi, A.; Guo, S.; Nomiyama, T. Self-standing conductive ITO-silica nanofiber mats for use in flexible electronics and their application in dye-sensitized solar cells. Ceram. Int. 2017, 43, 8146-8152. [CrossRef]

21. Newsome, T.E.; Olesik, S.V. Silica-based nanofibers for electrospun ultra-thin layer chromatography. J. Chromatogr. A 2014, 1364, 261-270. [CrossRef] [PubMed]

22. Chen, L.J.; Liao, J.D.; Lin, S.J.; Chuang, Y.J.; Fu, Y.S. Synthesis and characterization of PVB/silica nanofibers by electrospinning process. Polymer 2009, 50, 3516-3521. [CrossRef]

23. Choi, S.S.; Lee, S.G.; Im, S.S.; Kim, S.H.; Joo, Y.L. Silica nanofibers from electrospinning/sol-gel process. J. Mater. Sci. Lett. 2003, 22, 891-893. [CrossRef]

24. Maheswari, D.K.; Sreenivasan, D. Review of $\mathrm{TiO}_{2}$ nanowires in dye sensitized solar cell. Appl. Sol. Energy 2015, 51, 112-116. [CrossRef] 
25. Pu, Y.C.; Wang, G.; Chang, K.D.; Ling, Y.; Lin, Y.K.; Fitzmorris, B.C.; Liu, C.-M.; Lu, X.; Tong, Y.; Zhang, J.Z.; et al. Au nanostructure-decorated $\mathrm{TiO}_{2}$ nanowires exhibiting photoactivity across entire UV-visible region for photoelectrochemical water splitting. Nano Lett. 2013, 13, 3817-3823. [CrossRef] [PubMed]

26. Pu, Y.C.; Ling, Y.; Chang, K.D.; Liu, C.M.; Zhang, J.Z.; Hsu, Y.J.; Li, Y. Surface passivation of $\mathrm{TiO}_{2}$ nanowires using a facile precursor-treatment approach for photoelectrochemical water oxidation. J. Phys. Chem. C 2014, 118, 15086-15094. [CrossRef]

27. Chiu, Y.H.; Hsu, Y.J. Au@Cu7S4 yolk@ shell nanocrystal-decorated $\mathrm{TiO}_{2}$ nanowires as an all-day-active photocatalyst for environmental purification. Nano Energy 2017, 31, 286-295. [CrossRef]

28. Chang, Y.S.; Choi, M.; Baek, M.; Hsieh, P.Y.; Yong, K.; Hsu, Y.J. CdS/CdSe co-sensitized brookite H: TiO 2 nanostructures: Charge carrier dynamics and photoelectrochemical hydrogen generation. Appl. Catal. B 2018, 225, 379-385. [CrossRef]

29. Nishikawa, H.; Shiroyama, T.; Nakamura, R.; Ohki, Y.; Nagasawa, K.; Hama, Y. Photoluminescence from defect centers in high-purity silica glasses observed under 7.9-eV excitation. Phys. Rev. B 1992, 45, 586. [CrossRef]

30. Lin, J.; Huang, Y.; Zhang, J.; Gao, J.; Ding, X.; Huang, Z.; Chen, D. Characterization and photoluminescence properties of $\mathrm{Tb}$-doped $\mathrm{SiO}_{2}$ nanowires as a novel green-emitting phosphor. Chem. Mater. 2007, 19, 2585-2588. [CrossRef]

31. Yu, D.P.; Hang, Q.L.; Ding, Y.; Zhang, H.Z.; Bai, Z.G.; Wang, J.J.; Feng, S.Q. Amorphous silica nanowires: Intensive blue light emitters. Appl. Phys. Lett. 1998, 73, 3076-3078. [CrossRef]

32. Zong, X.; Cai, Y.; Sun, G.; Zhao, Y.; Huang, F.; Song, L.; Wei, Q. Fabrication and characterization of electrospun $\mathrm{SiO}_{2}$ nanofibers absorbed with fatty acid eutectics for thermal energy storage/retrieval. Sol. Energy Mater. Sol. Cells 2015, 132, 183-190. [CrossRef]

33. Wang, X.; Xi, M.; Wang, X.; Fong, H.; Zhu, Z. Flexible composite felt of electrospun $\mathrm{TiO}_{2}$ and $\mathrm{SiO}_{2}$ nanofibers infused with $\mathrm{TiO}_{2}$ nanoparticles for lithium ion battery anode. Electrochim. Acta 2016, 190, 811-816. [CrossRef]

34. Batool, S.S.; Imran, Z.; Hassan, S.; Rasool, K.; Ahmad, M.; Rafiq, M.A. Enhanced adsorptive removal of toxic dyes using $\mathrm{SiO}_{2}$ nanofibers. Solid State Sci. 2016, 55, 13-20. [CrossRef]

35. Tański, T.; Matysiak, W.; Hajduk, B. Manufacturing and investigation of physical properties of polyacrylonitrile nanofibre composites with $\mathrm{SiO}_{2}, \mathrm{TiO}_{2}$ and $\mathrm{Bi}_{2} \mathrm{O}_{3}$ nanoparticles. Beilstein J. Nanotechnol. 2016, 7, 1141-1155. [CrossRef] [PubMed]

36. Swanepoel, R. Determination of surface roughness and optical constants of inhomogeneous amorphous silicon films. J. Phys. E Sci. Instrum. 1984, 17, 896. [CrossRef]

37. Tański, T.; Matysiak, W.; Krzemiński, Ł. Analysis of optical properties of $\mathrm{TiO}_{2}$ nanoparticles and $\mathrm{PAN} / \mathrm{TiO}{ }_{2}$ composite nanofibers. Mater. Manuf. Process. 2017, 32, 1218-1224. [CrossRef]

38. Jarka, P.; Tański, T.; Matysiak, W.; Krzemiński, Ł.; Hajduk, B.; Bilewicz, M. Manufacturing and investigation of surface morphology and optical properties of composite thin films reinforced by $\mathrm{TiO}_{2}, \mathrm{Bi}_{2} \mathrm{O}_{3}$ and $\mathrm{SiO}_{2}$ nanoparticles. Appl. Surf. Sci. 2017, 424, 206-212. [CrossRef]

39. Tański, T.; Matysiak, W.; Krzemiński, Ł.; Jarka, P.; Gołombek, K. Optical properties of thin fibrous $\mathrm{PVP} / \mathrm{SiO}_{2}$ composite mats prepared via the sol-gel and electrospinning methods. Appl. Surf. Sci. 2017, 424, 184-189. [CrossRef]

40. Ramalla, I.; Gupta, R.K.; Bansal, K. Effect on superhydrophobic surfaces on electrical porcelain insulator, improved technique at polluted areas for longer life and reliability. Int. J. Eng. Technol. 2015, 4, 509. [CrossRef]

41. Lin, J.Y.; Wang, B.X. Room-temperature voltage stressing effects on resistive switching of conductive-bridging RAM cells with Cu-doped $\mathrm{SiO}_{2}$ films. Adv. Mater. Sci. Eng. 2014. [CrossRef]

42. Poliah, R.; Sreekantan, S. Characterization and photocatalytic activity of enhanced copper-silica-loaded titania prepared via hydrothermal method. J. Nanomater. 2011, 58. [CrossRef]

43. Budiarti, H.A.; Puspitasari, R.N.; Hatta, A.M.; Risanti, D.D. Synthesis and Characterization of $\mathrm{TiO}_{2} @ \mathrm{SiO}_{2}$ and $\mathrm{SiO}_{2} @ \mathrm{TiO}_{2}$ Core-Shell Structure Using Lapindo Mud Extract via Sol-Gel Method. Procedia Eng. 2017, 170, 65-71. [CrossRef]

44. Liu, Z.; Jian, Z.; Fang, J.; Xu, X.; Zhu, X.; Wu, S. Low-temperature reverse microemulsion synthesis, characterization, and photocatalytic performance of nanocrystalline titanium dioxide. Int. J. Photoenergy 2012. [CrossRef] 
45. Malitson, I.H. Interspecimen comparison of the refractive index of fused silica. JOSA 1965, 55, 1205-1209. [CrossRef]

46. Bodurov, I.; Vlaeva, A.; Viraneva, T.; Yovcheva, S. Modified design of a laser refractometer. Nanosci. Nanotechnol. 2016, 16, 31-33.

47. Siefke, T.; Kroker, S.; Pfeiffer, K.; Puffky, O.; Dietrich, K.; Franta, D.; Ohlídal, I.; Szeghalmi, A.; Kley, E.-B.; Tünnermann, A. Materials pushing the application limits of wire grid polarizers further into the deep ultraviolet spectral range. Adv. Opt. Mater. 2016, 4, 1780-1786. [CrossRef]

48. Kischkat, J.; Peters, S.; Gruska, B.; Semtsiv, M.; Chashnikova, M.; Klinkmüller, M.; Fedosenko, O.; Machulik, S.; Aleksandrova, A.; Monastyrskyi, G.; et al. Mid-infrared optical properties of thin films of aluminum oxide, titanium dioxide, silicon dioxide, aluminum nitride, and silicon nitride. Appl. Opt. 2012, 51, 6789-6798. [CrossRef] [PubMed]

49. Devore, J.R. Refractive indices of rutile and sphalerite. J. Opt. Soc. Am. 1951, 41, 416-419. [CrossRef]

50. Lucarini, V.; Saarinen, J.J.; Peiponen, K.E.; Vartiainen, E.M. Kramers-Kronig Relations in Optical Materials Research (Vol. 110), 1st ed.; Springer: Berlin/Heidelberg, Germany, 2005; ISBN 9783540236733.

51. Thangavel, K.; Balamurugan, A.; Venkatachalam, T.; Kumar, E.R. Structural, morphological and optical properties of ZnO nano-fibers. Superlattices Microstruct. 2016, 90, 45-52. [CrossRef]

52. Matysiak, W.; Tański, T.; Zaborowska, M. Manufacturing process, characterization and optical investigation of amorphous 1D zinc oxide nanostructures. Appl. Surf. Sci. 2018. [CrossRef]

53. Nekrashevich, S.S.; Gritsenko, V.A. Electronic structure of silicon dioxide (a review). Phys. Solid State 2014, 56, 207-222. [CrossRef]

54. Nandanwar, R.; Singh, P.; Haque, F.Z. Synthesis and Characterization of $\mathrm{SiO}_{2}$ Nanoparticles by Sol-Gel Process and Its Degradation of Methylene Blue. Am. Chem. Sci. J. 2015, 5, 1-10. [CrossRef]

(C) 2018 by the authors. Licensee MDPI, Basel, Switzerland. This article is an open access article distributed under the terms and conditions of the Creative Commons Attribution (CC BY) license (http:/ / creativecommons.org/licenses/by/4.0/). 